\title{
miR-218 Expressed in Endothelial Progenitor Cells Contributes to the Development and Repair of the Kidney Microvasculature
}

Xiaojie Wang, ${ }^{* \dagger}$ Jialing Liu, ${ }^{* \ddagger}$ Wenqing Yin, ${ }^{*}$ Farhiya Abdi, ${ }^{*}$ Paul D. Pang, ${ }^{*}$ Quynh-Anh Fucci, ${ }^{*}$ Molly Abbott, ${ }^{*}$ Steven L. Chang, ${ }^{\S}$ Graeme Steele, ${ }^{\S}$ Ankit Patel, ${ }^{*}$ Yutaro Mori, ${ }^{*}$ Aifeng Zhang, ${ }^{*}$ Shikai Zhu, ${ }^{*}$ Tzong-Shi Lu, * Adam S. Kibel, Bin Wang, ${ }^{*}$ Kenneth Lim, ${ }^{\top}$ and Andrew M. Siedlecki*

From the Department of Internal Medicine,* and the Urology Division,,$^{\S}$ Department of Surgery, Brigham and Women's Hospital, and the Department of Internal Medicine, ${ }^{\rrbracket}$ Massachusetts General Hospital, Harvard Medical School, Boston, Massachusetts; Department of Pharmacology, ${ }^{\dagger}$ School of Basic Medical Sciences, Shandong University, Jinan, China; Department of Nephrology, ${ }^{\ddagger}$ The Second Affiliated Hospital of Guangzhou University of Chinese Medicine, Guangzhou, China

Accepted for publication November 8, 2019.

Address correspondence to Andrew M. Siedlecki, M.D., Harvard Institutes of Medicine, 77 Ave. Louis Pasteur, HIM Rm 568B, Boston, MA 02115. E-mail: asiedlecki@ partners.org.

\begin{abstract}
Ischemia due to hypoperfusion is one of the most common forms of acute kidney injury. We hypothesized that kidney hypoxia initiates the up-regulation of miR-218 expression in endothelial progenitor cells (EPCS) to guide endocapillary repair. Murine renal artery-derived EPCS $\left(\mathrm{CD}^{2} 4^{+} / \mathrm{CD}{ }^{-} 5^{-}\right)$showed down-regulation of $m m u$-Mir218-5p/U6 RNA ratio after ischemic injury, while in human renal arteries, MIR218-5p expression was up-regulated after ischemic injury. MIR218 expression was clarified in cell culture experiments in which increases in both SLIT3 and MIR218-2-5p expressions were observed after 5 minutes of hypoxia. ROBO1 transcript, a downstream target of MIR218-2-5p, showed inverse expression to MIR218-2-5p. EPCs transfected with a MIR218-5p inhibitor in three-dimensional normoxic culture showed premature capillary formation. Organized progenitor cell movement was reconstituted when cells were co-transfected with Dicer siRNA and low-dose Mir218-5p mimic. A Mir218-2 knockout was generated to assess the significance of miR218-2 in a mammalian model. Mir218-2-5p expression was decreased in Mir218-2 ${ }^{-/-}$embryos at E16.5. Mir218-2 ${ }^{-/-}$decreased CD34 $4^{+}$angioblasts in the ureteric bud at E16.5 and were nonviable. Mir218-2 $2^{+/-}$ decreased peritubular capillary density at postnatal day 14 and increased serum creatinine after ischemia in adult mice. Systemic injection of miR-218-5p decreased serum creatinine after injury. These experiments demonstrate that miR-218 expression can be triggered by hypoxia and modulates EPC migration in the kidney. (Am J Pathol 2020, 190: 642-659; https://doi.org/10.1016/j.ajpath.2019.11.014)
\end{abstract}

Ischemia is a leading cause of kidney injury among patients receiving health care in the United States. ${ }^{1-3}$ Endothelial cells in the renal vascular system undergo substantial damage and necrosis after an ischemic episode and do not recover as efficiently as do tubular epithelial cells (TECs). ${ }^{3-5}$ Endothelial migration has long been proposed as a compensatory mechanism in the setting of reduced nephron mass but has not been investigated in the setting of ischemic kidney injury. ${ }^{6}$ miR-218 is recognized to play a functional role in human endothelial cells, with inhibition conferring a migratory phenotype. ${ }^{7,8}$ However, the effect of mature miR-218 miRNA products has not been clearly described. miR-218 is a pre-miRNA sequence located in the noncoding region of the Slit guidance ligands 2 and 3 host genes (SLIT2 and SLIT3). These two genes are located in the mouse genome on chromosomes 5 and 11, and in the human genome on chromosomes 4 and 5, respectively. After a

Supported by NIH grant K08DK089002 (A.M.S), a Brigham and Women's Hospital Faculty Career Development Award (A.M.S.), and University of Alabama at Birmingham/University of California-San Diego O'Brien Core Center for Acute Kidney Injury Research grant NIH P30 DK 079337.

X.W. and J.L. contributed equally to this work.

Disclosures: A provisional patent was filed on December 5, 2019, titled Methods and Materials for Kidney Endothelial Progenitor Cells (application number 62/944,036; A.M.S.). 
series of ligation steps, pre-miRNA is cleaved to form mature miRNA (Figure 1). Mature miR-218 effectors include miR-218-1-5p, miR-218-1-3p, miR-218-2-5p, and miR-218-2-3p. Unlike miR-218-3p, both mature miR-218$5 \mathrm{p}$ sequences are identical in mice and humans, demonstrating complete conservation between these two species and inferring physiologic relevance. Mature miR-218 has an effect on cellular function by interacting with transcription targets such as roundabout guidance receptor (ROBO)-1 and modulating cell migration. ${ }^{7,9}$ Other groups have concluded that SLIT2 is activated after exposure of neurons to hypoxia, noting that miR-218-1 is found within the SLIT2 gene. ${ }^{10}$ The relationship between SLIT3/miR-218/ROBO1 expression in endothelial progenitor cells (EPCs) and renal hypoxia has not been described.

$\mathrm{CD} 34^{+} / \mathrm{CD} 105^{-}$cells derived from the renal artery have been characterized as an EPC type and termed renal artery-derived EPCs (RAPCs) that express miR-218. ${ }^{8}$ This study demonstrates that miR-218 localizes to the vasculature of both the murine and human kidney. More specifically, miR-218-5p is expressed in EPCs present both in embryos and adults. Expression of mature miR-218-5p is highly susceptible to hypoxia and, when dysregulated, impairs capillary development.

\section{Materials and Methods}

\section{microRNA Microarray}

Mouse renal artery tissue was procured from animals that underwent microvascular clamp-induced ischemic injury for 30 minutes compared to animals that underwent a sham procedure as previously described. ${ }^{8,11}$ Immediately after microvascular clamping was disengaged, renal artery tissue was procured. Care was taken in mice to place microvascular clamps at the proximal portion of the renal artery. Mouse renal artery tissue was procured from the distal segment of the renal artery to avoid instrumented areas. Once extracted, renal artery tissue was digested with Type II collagenase (Stemcell Technologies, Vancouver, BC, Canada). Single cells were sorted for CD34 surface expression in the absence of CD105. miRNA was extracted with the Ambion mirVana kit (Thermo Fisher Scientific, Inc., San Diego, CA) following the manufacturer's instructions. cDNA was generated with M-MLV Reverse Transcriptase (Promega, Inc., Madison, WI). The 7900HT Fast Real-Time PCR System (Life Technologies, Inc., Carlsbad, CA) was used for analyzing TaqMan MicroRNA (757 target sequences excluding endogenous controls) arrays (Life Technologies, Inc.) aligned in a preconfigured 384-well microfluidic card. Target sequences were designed from information found in miRBase version 17 (http://www. miRbase.org). Initial animal group amplification plots were analyzed using SymphoniSuite software version 1.2 (Life Technologies, Inc.). Results were normalized as recommended for miRNA microarray studies. ${ }^{12}$ Data were deposited in the National Center for Biotechnology Information Gene Expression Omnibus (http://www.ncbi.nlm. nih.gov/geo) using a series reference GSE68369. Antisense miRNA probes detecting transcript were reviewed for further analysis when absolute cycle time was $<30$, independent sample $t$-test reported $\geq 6 \mathrm{df}$ among samples, and
A
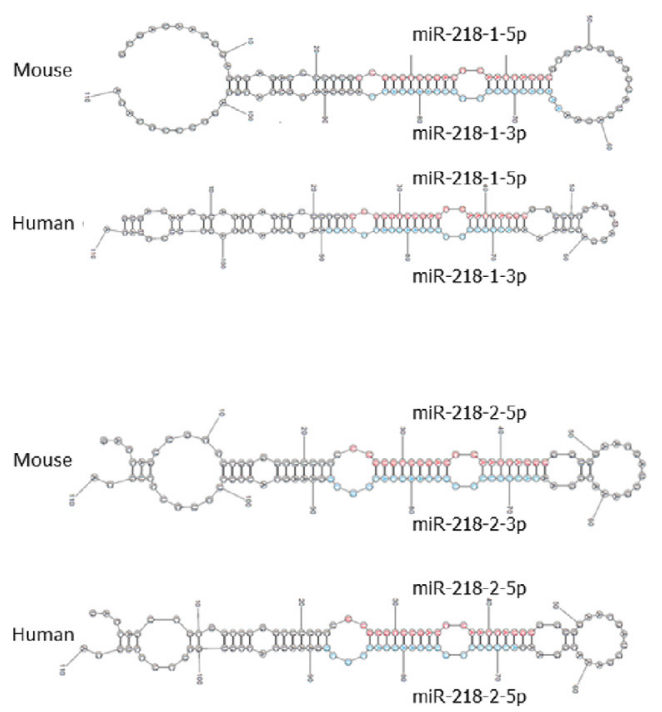

B

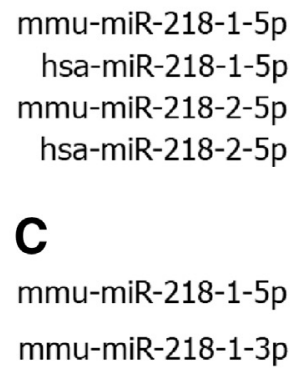

$$
\begin{aligned}
& \text { hsa-miR-218-1-5p } \\
& \text { hsa-miR-218-1-3p } \\
& \text { mmu-miR-218-2-5p } \\
& \text { mmu-miR-218-2-3p } \\
& \text { hsa-miR-218-2-5p } \\
& \text { hsa-miR-218-2-3p }
\end{aligned}
$$

$$
\begin{array}{ll}
\text { uugugcuugaucuaaccaugu } & \text { Mouse } \\
\text { uugugcuugaucuaaccaugu } & \text { Human } \\
\text { uugugcuugaucuaaccaugu } & \text { Mouse } \\
\text { uugugcuugaucuaaccaugu } & \text { Human }
\end{array}
$$

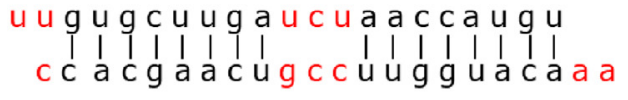

Figure 1 miR-218 conformations found in mice ( $\mathrm{mmu}$ ) and humans (hsa). A: Stem-loop projections of pre-miR-218 in mice and humans. B: Paralogous and orthologous mature MIR218-5p nucleotide sequences in mouse and human species. C: Complementary MIR218-5p nucleotide sequences (black letters), noncomplementary nucleotides (red letters), and corresponding mature MIR218-3p sequences in mouse and human species. 
the mean difference between groups was $>1.0 . P$ values were adjusted for multiple testing using the BenjaminiHochberg correction to account for false-discovery rate. ${ }^{13}$

\section{Human Renal Artery Procurement}

The Partners Healthcare Institutional Review Board approved the study protocol on May 16, 2013, utilized to obtain human tissue. This protocol is renewed each year and remains active. Written consent was obtained from all participating patients prior to study enrollment and tissue procurement. The Brigham and Women's Hospital provides inpatient surgical services for the Dana Farber Cancer Institute (Boston, MA), a tertiary care referral center for the treatment of renal cell cancer. All nephrectomies were performed laparoscopically. Pneumoperitoneum was induced to visualize the operative field. Insufflation of carbon dioxide maintained an intra-abdominal pressure of 12 to 15 $\mathrm{mmHg}$. Warm ischemia time was measured from the time of renal artery cross-clamp to the time tissue was taken out of the abdomen and placed in an ice chest available in the operative suite. Samples were transported on ice to the laboratory for processing and/or storage. In vitro cell culture was stored in liquid nitrogen and vials were de-identified. Once in vitro cell culture yielded $80 \%$ confluency, cells were stored in coded vials in liquid nitrogen. Tissue was prepared for in situ hybridization by placement of the tissue in $4 \%$ paraformaldehyde, transfer to $30 \%$ sucrose, and finally stabilization in optical cutting temperature compound (Takeda, Inc., Lincolnshire, IL).

\section{In Situ Hybridization}

Tissue cross sections (8-micron thickness) were separately treated with the Mir218-5p detection probe (Qiagen/Exiqon Inc., Woburn, MA). Detection probes unique for miRNA ascribed to Homo sapiens (hsa)- and Mus musculus (mmu) Mir218-2-3p were also utilized since each $3 p$ mature miRNA is not fully complementary (90.9\%) (Figure 1). Separate miRCURY locked nucleic acid used 5'-DIG and
$3^{\prime}$-DIG label to localize probe binding to histologic sections. Tissue was processed according to the manufacturer's instructions. For clinical studies, $h s a-M I R 218-5 p$ miRCURY locked nucleic acid detection probe, with 5'-DIGN/ ACATGGTTAGATCAAGCACA/DIGN-3', was used. Probe was diluted to 1:450. Anti-digoxigenin secondary antibody (F. Hoffmann-La Roche Ltd, Basel, Switzerland) was conjugated to alkaline phosphatase. Alkaline phosphatase incubation was performed for 2 hours. Nitro blue tetrazolium chloride (Roche) was used as a substrate to create a blue-black precipitate, formazan, at the location of locked nucleic acid probe binding. Tissue samples were quantitated using five high-power fields with 25 to 45 nuclei per field. A nuclear-fast red-stained cell was scored as positive (blue/black color) when greater than two-thirds of the nucleus was homogenously opacified by formazan precipitate. When less than two-thirds of the nucleus was opacified, or punctate precipitates were present, the cell was scored as negative. Probe aliquots were diluted to 1:450 for each histologic slide preparation. Alkaline phosphatase incubation was performed for 2 hours.

\section{Immunofluorescence Microscopy}

Human and adult mouse tissue was fixed in $4 \%$ paraformaldehyde for 45 minutes, then $30 \%$ sucrose for 18 hours, then placed in optimum cutting temperature compound (Fisher Scientific, Hampton, NH), bathed in liquid nitrogen and stored at $-80^{\circ} \mathrm{C}$. Embryonic mouse tissue was fixed in 5\% paraformaldehyde overnight, then $70 \%$ alcohol, and finally paraffin embedded. Standard xylene deparaffinization technique was used, followed by $70 \%$ ethanol wash to avoid excessive dehydration. Primary antibodies with epitope specific to mouse and human tissue were used (Table 1).

Human tissue sections were evaluated for antigens specifically binding to anti-human epitopes (Table 1). On analysis of tissue for co-localization of cell surface proteins and intracellular miRNA, adjacent microtomed sections were utilized. Immunofluorescence was performed using fluorescein isothiocyanate goat anti-mouse IgG, secondary antibody (dilution

Table 1 Primary and Secondary Antibody Specifications

\begin{tabular}{llll}
\hline Epitope & Product name & Host species & Company \\
\hline CD105 & Anti-CD105 antibody (SN6) & Mouse & Abcam, Cambridge, MA \\
CD105 & CD105 (endoglin) monoclonal antibody (MJ7/18) & Rat & eBioscience, San Diego, CA \\
CD34 & Anti-CD34 antibody & Rabbit & Abcam \\
EPCAM & Anti-EpCAM antibody (EGP40/1110) - BSA and azide free & Mouse & Abcam \\
CD31 & CD31 (PECAM-1) monoclonal antibody (390) & Rat & eBioscience \\
HIF-1 $\alpha$ & Anti & Mouse & Abcam \\
Dicer & Anti-Dicer antibody (13D6)-ChIP grade & Mouse & Abcam \\
R0B01 & Anti-Robo1 antibody & Rabbit & Abcam \\
Slit3 & Anti-Slit3 & Rabbit & Sigma-Aldrich, St. Louis, M0 \\
$\beta$-Actin & $\beta$-Actin monoclonal antibody (AC-15) & Mouse & Thermo Fisher Scientific \\
\hline
\end{tabular}

BSA, bovine serum albumin; EPCAM, epithelial cell adhesion molecule; HIF, hypoxia-inducible factor; PECAM, platelet endothelial cell adhesion molecule; ROBO, roundabout homolog; SLIT, Slit homolog protein. 
miR-218 in Kidney Repair

Table 2 Risk Factors Implicated in $\geq 10 \mathrm{~mL} /$ minute $/ 1.73 \mathrm{~m}^{2}$ Decline in Kidney Function $>90$ Days after Radical Nephrectomy

\begin{tabular}{|c|c|c|c|c|}
\hline & $\chi^{2}$ & Odds ratio & Confidence interval & $P$ value \\
\hline DM & 0.24 & 1.90 & $0.50-7.81$ & NS \\
\hline Age $<60$ years & 0.23 & 0.29 & $0.91-6.11$ & NS \\
\hline Tumor $>4 \mathrm{~cm}$ & 0.23 & 2.19 & $0.54-5.31$ & NS \\
\hline eGFR $<60 \mathrm{~mL} /$ minute per $1.73 \mathrm{~m}^{2}$ & 0.42 & 1.54 & $0.74-2.31$ & NS \\
\hline Glomerulosclerosis >30\% & 0.80 & 0.57 & $0.17-1.98$ & NS \\
\hline $\mathrm{CCI}<90$ & 3.25 & 2.31 & $0.90-5.93$ & NS \\
\hline BMI $<30 \mathrm{~kg} / \mathrm{m}^{2}$ & 3.58 & 1.39 & $0.97-1.97$ & NS \\
\hline WIT $\geq 31$ minutes & 3.71 & 1.17 & $0.05-2.40$ & * \\
\hline MIR218 $\mathrm{Hi}$ & 8.64 & 3.01 & $0.08-0.82$ & ** \\
\hline
\end{tabular}

${ }^{*} P<0.05,{ }^{*} P<0.01$

BMI, body mass index; CCI, Charlson comorbidity index; DM, diabetes mellitus; eGFR, estimated glomerular filtration rate; F, female; NS, nonsignificant; WIT, warm ischemia time.

1:200, Jackson Immunoresearch Laboratories, West Grove, PA), and cy3 goat anti-rabbit IgG secondary antibody (dilution 1:300, Jackson Immunoresearch). All immunofluorescencebased image capture was performed using the Nikon Eclipse 80i Multiphoton Confocal Microscope with NIS-Elements imaging/analysis software AR version 3.2 (Nikon Instruments, Melville, NY). Primary and secondary antibodies were used as previously described ${ }^{8,14}$ (Table 1).

\section{Patient Selection Criteria}

All patients had a primary follow-up at the Brigham and Women's Hospital and/or Dana Farber Cancer Institute, which allowed for monitoring via the common Epic electronic medical record system (Epic Systems Corporation, Verona, WI). Patient characteristics were analyzed for potential association with a decline in kidney function (Table 1). Postoperative serum creatinine measured the function of the remaining contralateral kidney. The serum creatinine measured the general response of nonmalignant kidney tissue to a mild ischemic insult due to increased abdominal pressure present during laparoscopic surgical techniques. RAPCs were routinely isolated and cultured after nephrectomies with a mean warm ischemic time of $33.0 \pm 3.6$ minutes.

Patients were followed prospectively from the time of surgery to the last clinic visit prior to October 31, 2017. Patient follow-up information included renal function, hospitalization, and death status. Renal function was estimated using the sixvariable Modification of Diet in Renal Disease study equation. ${ }^{15}$ Patients were excluded from the study for any of the following: stroke; myocardial infarction; heart failure; liver disease at the time of surgery; metastatic cancer after surgery involving the kidney, kidney collecting system, or bladder; monoclonal gammopathy of unknown significance; multiple myeloma; tumor lysis syndrome. Patients grouped by MIR218$5 p$ expression had similar preoperative blood pressure, ethnicity, sex, and nonmalignant histologic scoring at the time of nephrectomy (Table 2). The difference in histologic grades of interstitial fibrosis and tubular atrophy in the nonmalignant renal cortex between patient groups was not statistically significant. Mortality was not associated with MIR218-5p expression. Covariates potentially linked to $-\Delta \mathrm{eGFR}$ (inverse of the change in estimated glomerular filtration rate) were used for predictive modeling if the preoperative co-variates achieved a $P$ value of $<0.1$ by the $\chi^{2}$ test (Table 2). These included MIR218 expression, Charlson comorbidity index, and preoperative body mass index. The primary end point was defined as a death-censored decline in preoperative kidney function by $\geq 10 \mathrm{~mL} /$ minute per $1.73 \mathrm{~m}^{2}$ no less than 90 days after surgery. The mean follow-up time of $674 \pm 558$ days included patients who achieved the primary end point $>90$ days after surgery. One patient was censored before achieving a minimum postoperative follow-up duration due to death 29 days after surgery. All other patients who died $(n=7)$ achieved a follow-up time of at least 180 days. The primary end point was $-\Delta \mathrm{eGFR}$ of $\geq 10 \mathrm{~mL} /$ minute per $1.73 \mathrm{~m}^{2}$ occurring $>90$ days after nephrectomy. Diabetes, age at nephrectomy, and preoperative eGFR were included in initial analyses of risk factors for chronic kidney disease progression. End point of chronic kidney disease progression was achieved when eGFR was decreased by $10 \mathrm{~mL} /$ minute during the follow-up period, which could not be achieved until 90 days after surgery. This period allowed for compensatory hypertrophy of the contralateral kidney to be taken into account. Receiver operating characteristic curves were also constructed with validated risk factors of interest, including age, eGFR at the time of surgery, and diabetes mellitus status. The significance of area under the curve was based on the $U$-test.

\section{Renal Artery-Derived Endothelial Progenitor Cell Culture}

$\mathrm{CD} 34^{+} / \mathrm{CD} 105^{-}$for cell culture were isolated from euglycemic, nonsmokers, $<45$ years of age, with eGFR $>80 \mathrm{~mL} /$ minute per $1.73 \mathrm{~m}^{2}$ and an indication for nephrectomy as cancer therapy. Cell culture was performed as previously 
described. ${ }^{8}$ All experiments were performed after the first or second passage. Cells were allowed to adhere on a $3.2 \mathrm{~cm}^{2}$ sterile plastic surface coated with fibronectin and cultured in selective growth media containing basic fibroblast growth factor, ascorbic acid, hydrocortisone, without epidermal growth factor or vascular endothelial growth factor (VEGF). Cells were grown to $80 \%$ confluency and placed in a hypoxia incubator chamber (Stemcell Technologies) and flushed with $1 \% \mathrm{O}_{2}, 5 \% \mathrm{CO}_{2}$, and balanced $\mathrm{N}_{2}$ for 3 minutes to replace atmospheric oxygen with the hypoxic condition. The chamber was then sealed and then placed in a laboratory tissue culture incubator. Cell viability was assessed prior to protein and mRNA isolation. If $80 \%$ confluency was maintained after hypoxia exposure and $>80 \%$ of cells per high-power field were viable by morphology (absence of cytoplasmic vesicle) cells were then processed. The three-dimensional culture was performed in Matrigel as previously described. ${ }^{8}$ After VEGF stimulation ( $5 \mathrm{ng} / \mathrm{mL}$ ), angiogenesis was then quantitated. ${ }^{16}$ Transfection of siRNA for DICER was completed with lipofectamine 2000 (Thermo Fisher Scientific, Inc., Waltham, MA) according to the manufacturer's specifications. A $60 \%$ knockdown of DICER protein concentration was achieved during nonhypoxic conditions and $80 \%$ knockdown was achieved under hypoxic conditions (Supplemental Figure S1).

\section{Human Umbilical Vein Endothelial Cell Culture}

Human endothelial cells were purchased from (Lonza, Inc., Morristown, NJ) and cultured to $80 \%$ confluency in endothelial growth media (Lonza, Inc.) prior to hypoxia experiments under the same conditions as EPCs.

\section{Tubular Epithelial Cell Culture}

TECs were isolated by digesting a minced kidney with 1 $\mathrm{mg} / \mathrm{mL}$ collagenase type II for 40 minutes at $37^{\circ} \mathrm{C}$ and grown in Dulbecco's modified Eagle's medium/F12 50/50 media (Thomas Scientific, Swedesboro, NJ), supplemented with bovine serum albumin, hydrocortisone, and epidermal growth factor.

\section{Protein Analysis}

Cell lysate was processed and analyzed as previously described. ${ }^{8,17}$ Cytosolic protein lysates were prepared for immunoblot analysis using radioimmunoprecipitation assay lysis buffer $(50 \mathrm{mmol} / \mathrm{L}$ Tris/HCl pH 7.5,150 mmol/L NaCl, $10 \mathrm{mmol} / \mathrm{L} \mathrm{NaPPi}, 20 \mathrm{mmol} / \mathrm{L} \mathrm{NaF}, 1 \%$ sodium deoxycholate, $1 \%$ Triton, and $0.1 \%$ SDS). The protein concentration was measured using the bicinchoninic acid protein concentration assay kit (Sigma-Aldrich, Inc.) and adjusted to be consistent in each group. Then $50 \mu \mathrm{L}$ of protein extracts underwent gel electrophoresis with using NuPAGE Bis-Tris Gel cartridges (Invitrogen, Carlsbad, CA). Protein was then transferred on to a polyvinylidene fluoride membrane (Thermo Fisher Scientific, Inc.). Membranes were treated with $3 \%$ bovine serum albumin-blocking buffer in phosphate-buffered saline with azide (Boston BioProducts, Ashland, MA). Primary antibodies utilized are found in Table 1. The membrane was then incubated with goat antimouse IgG-horseradish peroxidase labeled secondary antibody (catalog number sc-2005; Santa Cruz Biotechnology, Dallas, TX) then briefly with electrogenerated chemiluminescence reaction solution (Thermo Fisher Scientific, Inc.). Images were acquired with a Bio-Rad gel imaging system (Bio-Rad Laboratories, Inc., Waltham, MA) and the gray value was analyzed by Image J software version 1.38e (NIH, Bethesda, MD; http://imagej.nih.gov/ij). All of the protein bands were analyzed by relative OD value. With $\beta$-actin as the internal reference, the ratios of OD values of target bands to $\beta$-actin bands, serve as their relative protein expression.

\section{Quantitative RNA Analysis}

Cell lysate was processed for separate analysis the intracellular concentration of mRNA and miRNA. ${ }^{17}$ RNA was extracted from cell lysates with TRIzol reagent (Invitrogen) for non-miRNA. miRNA was extracted with the mirVana kit (Ambion, Inc., Foster City, CA). RNA transcript was converted to complementary DNA using moloney murine leukemia virus reverse transcriptase. When quantifying levels of mature miRNA, reverse transcriptase primers corresponding with the species and gene locus of interest were added in the RT reaction. Corresponding cDNA samples then underwent quantitative PCR using primers specific to the mature miRNA in the gene locus of interest. Quantitative PCR was carried out on the Bio-Rad iQ5 realtime PCR system with the SYBR Green PCR detection kit (Bio-Rad), following the manufacturer's instructions. Denaturation temperature was $95^{\circ} \mathrm{C}(1$ minute), annealing temperature was $51^{\circ} \mathrm{C}$ (45 seconds), and extension temperature was $72^{\circ} \mathrm{C}$ (1 minute). Primer design was facilitated with MacVector Pro software version 16 (MacVector, Inc. Cary, NC). Primer sequences were as follows: reverse transcriptase primer human MIR218-1 (forward: 5'-GTCGTATCCAGTGCAGGGTCCGAGGTATTCGCACTGGATACGACCCATGG-3'), reverse transcriptase primer human MIR218-2 (forward: 5'-GTCGTATCCAGTGCAGGGTCCGAGGTATTCGCACTGGATACGACACATGG-3'), reverse transcriptase primer mouse Mir218-1 (forward: 5'-CCTCTCTCTGACGCTGCTTCCTGACCTTGACTCTGACCAGTCGCTGCGGGGCTTTCCT-3'), reverse transcriptase primer mouse Mir218-2 (forward: 5 '-CGCTGGACTCTTCTCTGCTCTGGATCACCGCGCCTGCCAGACCCACTTCTCCC-3'), human MIR218-1-5p (forward: 5'-GCGTGCTTGATCTAACCATGT-3'; reverse: 5'-GTGCAGGGTCCGAGGT-3'), human MIR218-1-3p (forward: 5'-ATGGTTCCGTCAAGCACCAT-3'; reverse: 5'-GTGCAGGGTCCGAGGT-3'), 
human MIR218-2-5p (forward: 5'-TCTGGCTTCAGCTTCTCCAC-3'; reverse: $5^{\prime}$-ATCAAGCACAAAGGAAAGCC-3'), human MIR218-2-3p (forward: 5'-ACGGAACATGGTTCTGTCAA-3'; reverse: 5'-TCCAGAGCAGAGAAGAGTCCA-3'), mouse Mir218-5p (Qiagen/Exiqon, Inc., Hilden, Germany), mouse Mir218-2-3p (forward: $5^{\prime}$ GAACGATGGAAACGGAACAT-3'; reverse: 5'-TCCAGAGCAGAGAAGAGTCCA-3'), U6 (forward: 5'-CTCGCTTCGGCAGCACA-3'; reverse: 5'-AACGCTTCACGAATTTGCGT-3'), SLIT2 (forward: 5'-CGGGTTGGTCTGTACACTCA-3'; reverse: 5'-CTGGTGACCACTGCAGACAA-3'), ROBO1 (forward: 5'-GCTACTCTGACTGTTCAAGAACCT-3'; reverse: 5'-GTCCGTCCCAAAGCAACAAC- ${ }^{\prime}$ ), SLIT3 (forward: 5' TCCAGTGCCAGGGGGTC-3'; reverse: 5'-GACCCCAGGCCAACATC-3'), and human MIR218-2 premiRNAs (forward: 5'-CTGCTCTGGCTTCAGCTTCT-3'; reverse: 5'-GCTGCTTCCTGACCTTGACT- $3^{\prime}$ ).

\section{Hypoxia Experiments}

Cells were placed in a hypoxia incubator chamber (Stem Cell Technologies, Inc.) and flushed with $1 \% \mathrm{O}_{2}, 5 \%$ $\mathrm{CO}_{2}$, and balanced $\mathrm{N}_{2}$ for 3 minutes. The chamber was sealed and then placed in a laboratory tissue culture incubator.

\section{Quantitation of Human Tubular Epithelial Cell/ Endothelial Progenitor Cell Interaction}

Matrigel $(240 \mu \mathrm{L})$ and RAPC media $(960 \mu \mathrm{L})$ were slowly mixed on ice to avoid bubbles. A total of $100 \mu \mathrm{L}$ of Matrigel was added to one of the 96-well plates and polymerized in a $37^{\circ} \mathrm{C}$ incubator for 1 hour. Human TECs were cultured to $90 \%$ confluence. TECs were trypsinized and resuspended in $5 \mathrm{~mL}$ of fetal bovine serum-containing medium and $30 \mu \mathrm{L}$ of CellTracker Green 5-chloromethylfluorescein diacetate (CMFDA; Invitrogen) $(5 \mu \mathrm{L} /$ $\mathrm{mL}$ ) and incubated at $37^{\circ} \mathrm{C}, 5 \% \mathrm{CO}_{2}$. EPCs were incubated with CellTracker CM-Dil (Invitrogen) $(3 \mu \mathrm{L} / \mathrm{mL})$ at $37^{\circ} \mathrm{C}, 5 \% \mathrm{CO}_{2}$ for 1 hour, then trypsinized to obtain a single-cell suspension and centrifuged 5 minutes at $90 \times g$. RAPCs were incubated with either scrambled anti-miRNA or anti-miR-218-5p (50 nmol/L) and then transferred to Matrigel. A total of $2 \times 10^{3}$ TECs and EPCs were separately injected to Matrigel in a 96-well plate. The analysis was completed in wells where linear distance $\left(\mathrm{d}_{0}\right)$ was 150 to $250 \mu \mathrm{mol} / \mathrm{L}$ between the leading edge of the EPC and TEC cell mass. The $\mathrm{d}_{0}$ between the leading edge of TECs and EPCs was measured at time 0. At 48 hours, perpendicular distance of the EPC leading edge was then calculated $\left(\mathrm{d}^{\prime}\right)$ by measuring the perpendicular distance from the location of the EPC leading edge at time 0. Migration index was calculated as $\mathrm{d}^{\prime} / \mathrm{d}_{0}$.
Endothelial Progenitor Cell Motility in Three-Dimensional Culture

Cells were cultured in Matrigel as previously described. ${ }^{8}$ Matrigel $20 \%$ was supplemented with VEGF $(5 \mathrm{ng} / \mathrm{mL})$ prior to cell delivery. Angiogenesis was then quantitated after 48 hours based on junction formation. ${ }^{16}$ Specific parameters included the number of endothelial projections, the length of endothelial projections, and the number of capillary loops.

\section{Mir218-2 CRISPR Knockout Model}

All research involving the use of mice was performed in strict accordance with protocols approved by the Animal Studies Committee of Harvard Medical School. A mouse model was designed to rapidly and specifically delete a $1.23-\mathrm{Kb}$ sequence that included the Mir218-2 pre-miRNA nucleotide sequence located on chromosome 11 within intron 14 of the Slit 3 gene. The open-access database (JASPAR, http://jaspar.genereg. net, last accessed September 12, 2018) of curated, nonredundant transcription factor-binding profiles was utilized for assessing for the deletion of potential transcription factor-binding sites. Single-guide RNA sequence designs were evaluated for off-target binding of exons using openaccess screening tools previously available at http://crispr. mit.edu (last accessed September 12, 2018; tool is no longer available). The following template was used for generating single guide (sg)RNA to selectively bind to the complementary $3^{\prime}$ genomic DNA sequence of interest: forward: $\quad 5^{\prime}$-AAACGGAGTGCGGTCCACTGGATCC-3' (Supplemental Figure S2). sgRNA was located 129 bp upstream of the first nucleotide in the Mir218-2 pre-miRNA sequence on the adjacent $5^{\prime}$ genomic DNA strand. sgRNA was selected based on in vitro binding assays confirmed by nucleotide sequencing (Supplemental Figure S2A). Corresponding chromatograms are available at https://data. mendeley.com/datasets $/ \mathrm{V} 7 x n \times 2 z 45 \mathrm{~g} / 1$. A linear 1226-bp construct was then designed to bind to the adjacent $3^{\prime}$ DNA strand and induce nonhomologous end-joining. Cytoplasmic injection of the sgRNA, linear construct, and $\operatorname{Cas} 9$ mRNA to embryos was performed in the Harvard University Transgenic Mouse Core, yielding four founder mice. Two sets of primers were used for genotyping to determine, first, whether the complete Mir218-2 pre-miRNA sequence was deleted from the mouse genome (forward: 5'-ATTGGATTTGCCTGGAGATGAGA-3'; reverse: 5'-CTGTGAGGATCCCTTGAGACCAG- $3^{\prime}$ ) and, second, whether the remaining sequence of intron 14 in the Slit3 gene was continuous (forward: $5^{\prime}$ TATGCACAGCTCTAGCG-3'; reverse: 5'-CTCCAGCCCAAA AGTGACAAC-3'). Genomic DNA was then sequenced for confirmation of the deletion (Supplemental Figure S2B). Corresponding chromatograms are available at https://doi.org/10.17632/v7 xnx2z45g.1 (Mir218-2 global knockout nucleotide sequences). Thirty-minute bilateral and 20-minute unilateral ischemia/reperfusion injury (IRI) was 
A
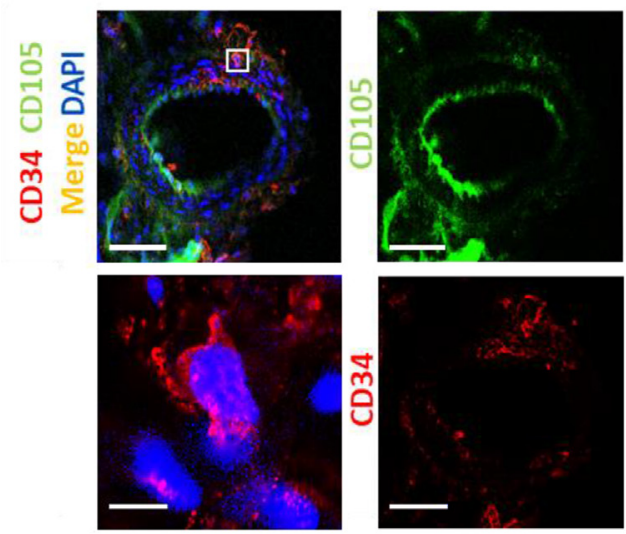

C

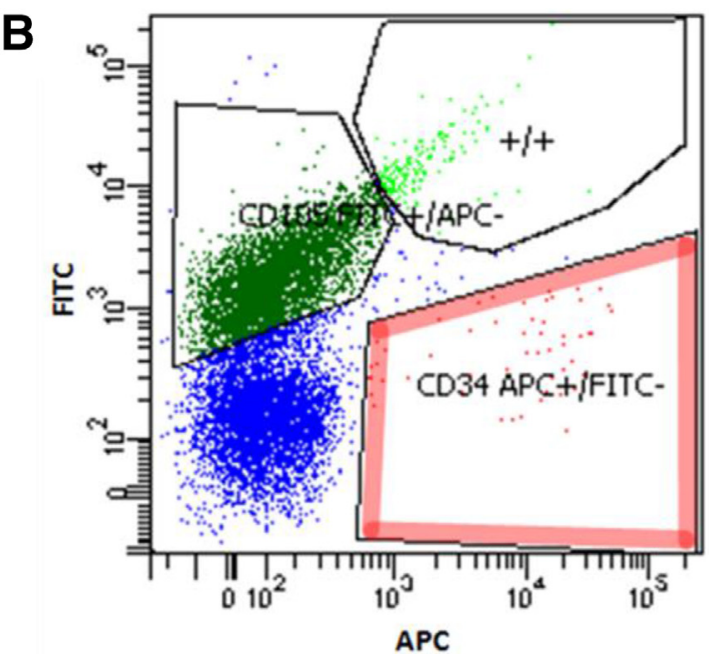

APC

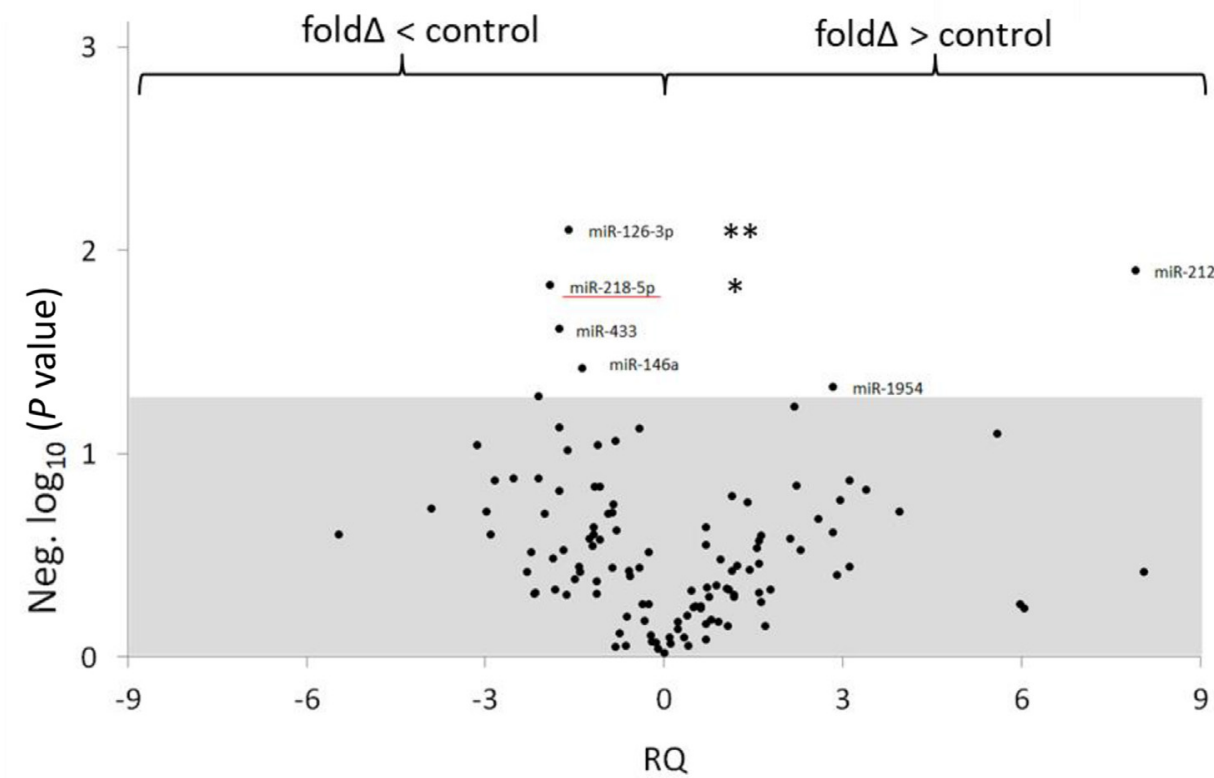

Figure 2 Mouse nephrectomy, renal artery isolation, and single-cell characterization of $\mathrm{CD} 34^{+} / \mathrm{CD} 105^{-}$by miRNA expression screening. A: $\mathrm{CD} 34^{+} / \mathrm{CD} 105^{-}$cells localize to the adventitia of mouse renal arteries [anti-CD34 antibody, cy3 secondary antibody (red); anti-CD105 antibody, fluorescein isothiocyanate (FITC) secondary antibody (green)]. Boxed area is shown at higher magnification below. B: Individually sorted cells selected positive for CD34 expression with mouse-specific anti-CD34 antibody [adenomatous polyposis coli (APC) conjugated] and negatively for CD105 expression (FITC conjugated). C: miRNA screen results plotting significant differences in miRNA expression against fold-changes in $\mathrm{CD}_{3} 4^{+} / \mathrm{CD} 105^{-}$cells extracted from the renal arteries of animals undergoing kidney-specific ischemic injury and from animals undergoing sham surgeries. Mean differences in PCR amplification product achieving threshold amplification when comparing cycle times between $\mathrm{CD}_{4} 4^{+} / \mathrm{CD} 105^{-}$derived from ischemia/reperfusion injury and sham control animals, with each sample group achieving $\geq 6 \mathrm{df}$ and all reactions with detected amplification meeting threshold at $<30$ cycle times. Relative quantitation of amplification products using anti-sense mmu-Mir218-2-5p and Mir126-3p achieved a mean fold-change of $\geq 1.5$ in ischemic samples compared to sham controls and maintained statistical significance [white section of graph, respectively represented as negative $\log _{10}(P$ value $\left.)\right]$. miR-218-5p in ischemic samples achieved the largest negative mean fold-change (underline). ${ }^{*} P<0.05,{ }^{* *} P<0.01$ versus control (adjusted). Scale bars: $100 \mu \mathrm{mol} / \mathrm{L}$ (A, top row); $5 \mu \mathrm{mol} / \mathrm{L}$ (A, bottom row).

performed as we previously described. ${ }^{11,14}$ Serum creatinine was measured using mass spectrometry at the University of Alabama (Birmingham, AL).

\section{In Vivo Injection of miR-218-5p Mimic}

miR-218-5p mimic $20 \mathrm{nmol} / \mathrm{L}$ of (Thermo Fisher) was resuspended in sterile normal saline and injected $(50 \mu \mathrm{L})$ i.v. by tail vein to pregnant heterozygotes that were mated to adult male heterozygotes. Control animals were given scrambled miRNA. The injection was given 10 days postcoitus, and kidneys were assessed at E16.5 by histologic techniques described in In Situ Hybridization. Surviving heterozygotes were maintained to adulthood (12 weeks), at which time serum creatinine was measured. Injection of mimic $(50 \mu \mathrm{L})$ in adult heterozygotes was performed 6 hours after unilateral IRI. 
A
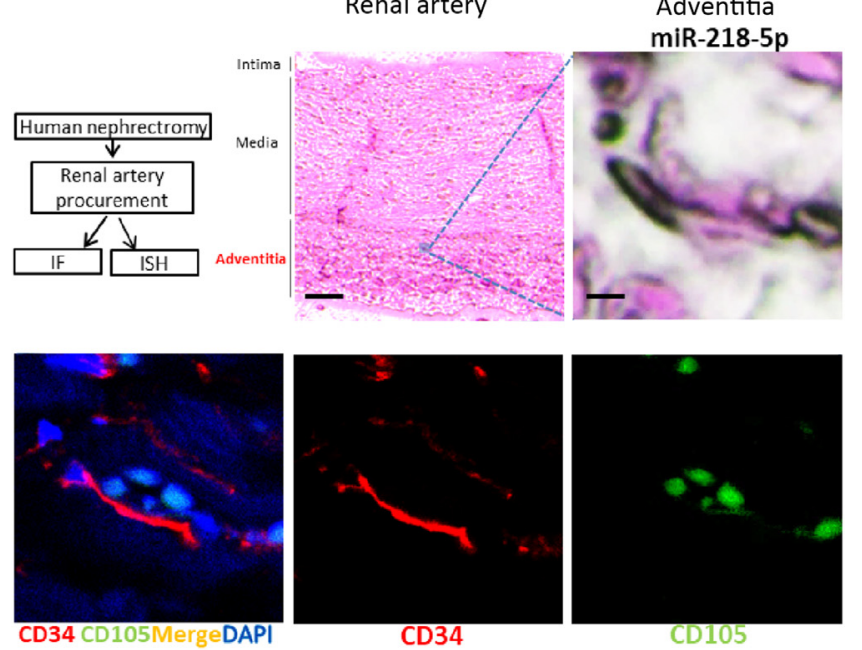

C

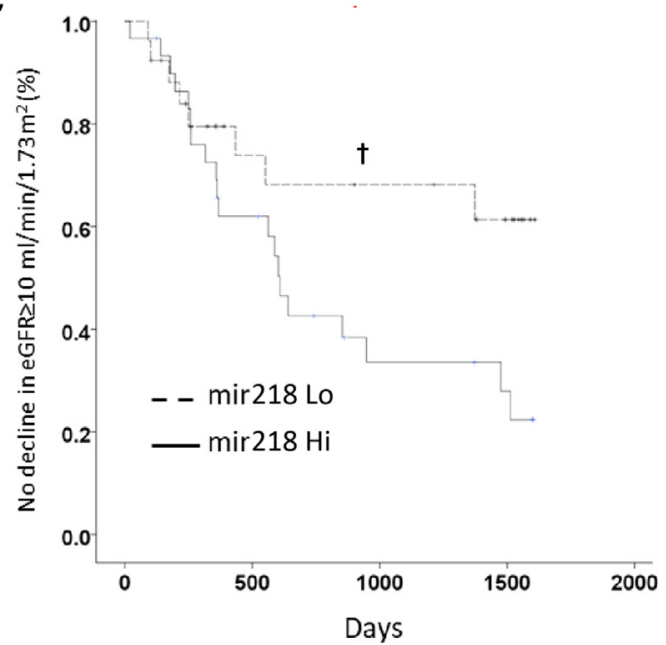

B

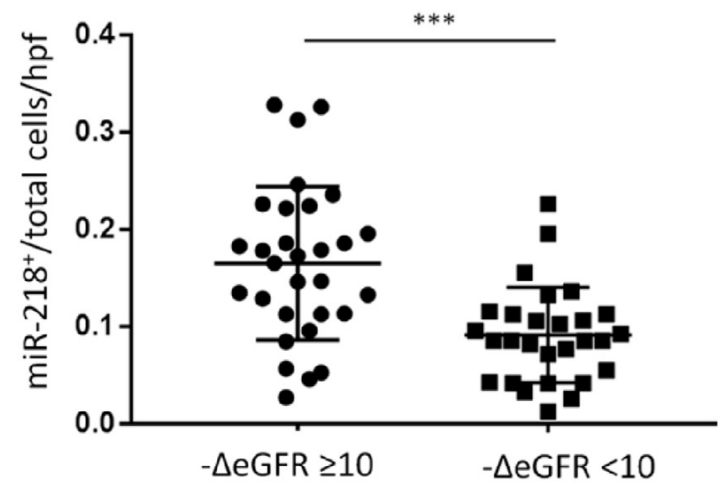

D

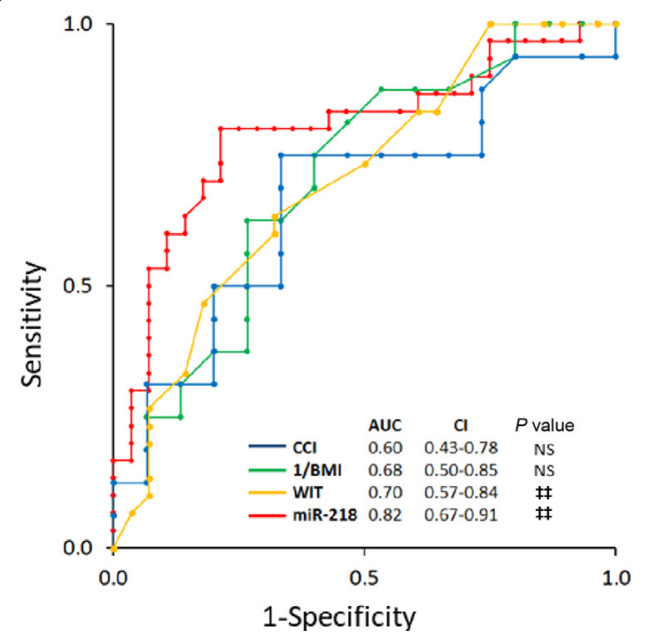

Figure 3 Screen for clinical significance of MIR218-5p expression in nonmalignant human renal artery tissue. A: Tissue was isolated and analyzed separately for specific binding of anti-CD34 antibody and anti-sense MIR218-5p oligomer. Renal artery was fixed, anti-sense probe conjugated to digoxigenin localized to cells in the adventitia. Adjacent cryotome tissue sections show cells binding MIR218-5p oligomer to co-localize with monoclonal anti-human CD34 antibody (red) rather than monoclonal anti-human CD105 antibody (green). B: Patients with $\geq 10 \mathrm{~mL} /$ minute per $1.73 \mathrm{~m}^{2}$ decline in renal function after nephrectomy display an increased number of MIR218 ${ }^{+}$cells per total cells per high-power field (hpf) in the adventitia of the renal artery compared to controls. C: Kaplan-Meier survival curve comparing patients with miR-218 $\mathrm{Hi}$ expression $\left(\geq 0.12 \mathrm{MIR} 218^{+} /\right.$total cells per hpf) to patients with miR-218 Lo expression $\left(<0.12 \mathrm{MIR} 218^{+} /\right.$ total cells per hpf) who had a decline in estimated glomerular filtration rate (eGFR) $\geq 10 \mathrm{~mL} /$ minute per $1.73 \mathrm{~m}^{2}$. D: Receiver operator characteristic curves compare the sensitivity and specificity of miR-218 expression, warm ischemia time (WIT), Charlson comorbidity index and 1/body mass index (BMI) to predict a decline in postoperative eGFR by $\geq 10 \mathrm{~mL} /$ minute per $1.73 \mathrm{~m}^{2} .{ }^{* *} P<0.001 ;{ }^{\dagger} P<0.05$ versus mir218 $\mathrm{Hi} ;{ }^{\ddagger \ddagger} P<0.01$ versus null hypothesis (AUC $=0.5$ ). Scale bars: $300 \mu \mathrm{mol} / \mathrm{L}$ (A, renal artery); $5 \mu \mathrm{mol} / \mathrm{L}$ (A, adventitia). Original magnification: $\times 800$ (A, bottom row). AUC, area under the curve.

\section{Statistical Analysis}

SPSS software version 22 (IBM, Inc., Armonk, NY) was used for all calculations. Patient characteristics for univariate analysis included the following categorical variables [age ( $>$ or $\leq 60$ years), tumor size $(>$ or $\leq 4 \mathrm{~cm})$, presurgery eGFR ( $>$ or $\leq 60 \mathrm{~mL} /$ minute per $1.73 \mathrm{~m}^{2}$ ), diabetes mellitus (yes/no), Charlson comorbidity index $(>90 \%$ or $\leq 90 \%)$, glomerulosclerosis ( $>$ or $\leq 10 \%$ ), interstitial fibrosis and tubular atrophy ( $>$ or $\leq 33 \%$ ), and arteriosclerosis $(>$ or $\leq 33 \%)$ ]. Covariates were selected for further evaluation if the significance threshold $(P<0.10)$ was met with the Mantel-Haenszel $\chi^{2}$ test. Cox regression analysis was used for studying time-dependent outcomes between patients in two groups: Lo expressors $\left(0-0.12 \mathrm{MIR} 218^{+}\right.$/ total cells per high-power field) and Hi expressors $(\geq 0.12$ $M I R 218^{+}$/total cells per high-power field). Patients were followed to the last clinic visit prior to December 1, 2017. Receiver operating characteristic curves were also constructed with validated risk factors of interest, including age, eGFR at the time of surgery, and diabetes mellitus status. ${ }^{18}$ The significance of area under the curve was based on the $U$ statistic. Experimental conditions in animals were evaluated for significance using analysis of variance in pairwise group comparison among multiple groups, along with the Bonferroni correction method. $t$-test was used for evaluating for significance (two-tailed) between two groups. All values represent the means \pm SD of a condition. 
Table 3 Patient Characteristics at Time of Therapeutic Nephrectomy

\begin{tabular}{|c|c|c|c|}
\hline Characteristic & MIR218 Lo $(n=30)$ & MIR218 Hi $(n=28)$ & $P$ value \\
\hline Age, years & $63.9 \pm 11.2$ & $59.9 \pm 15.0$ & NS \\
\hline Preoperative eGFR, $\mathrm{mL} /$ minute & $77.0 \pm 13.7$ & $75.7 \pm 21.8$ & NS \\
\hline Warm ischemia time, minutes & $31.6 \pm 4.1$ & $34.4 \pm 4.0$ & $* *$ \\
\hline Systolic, $\mathrm{mmHg}$ & $130 \pm 19$ & $134 \pm 22$ & NS \\
\hline Diastolic, $\mathrm{mmHg}$ & $75 \pm 12$ & $77 \pm 11$ & NS \\
\hline Nonblack ethnicity, \% & 95.8 & 90.0 & NS \\
\hline $\operatorname{Sex}(F), \%$ & 54.2 & 60.0 & NS \\
\hline Diabetes, \% & 25.0 & 20.0 & NS \\
\hline Metastasis, \% & 12.5 & 25.0 & NS \\
\hline Charlson comorbidity index, $\%$ & $84.8 \pm 17.9$ & $89.4 \pm 13.9$ & NS \\
\hline Body mass index, $\mathrm{kg} / \mathrm{m}^{2}$ & $29.5 \pm 7.9$ & $27.4 \pm 4.2$ & NS \\
\hline Glomerulosclerosis, ${ }^{\dagger} \%$ & $17 \pm 22$ & $17 \pm 15$ & NS \\
\hline Interstitial fibrosis, ${ }^{\dagger} \%$ & $24 \pm 24$ & $31 \pm 30$ & NS \\
\hline Arteriosclerosis, ${ }^{\dagger} \%$ & $2.3 \pm 0.6$ & $2.6 \pm 0.7$ & NS \\
\hline
\end{tabular}

$* * P<0.01$

${ }^{\dagger}$ Nonmalignant kidney tissue.

eGFR, estimated glomerular filtration rate; F, female.

\section{Results}

\section{miRNA Expression Screen in a Preclinical Model of Ischemic Kidney Injury}

We modeled kidney-specific ischemic injury in C57BL/6 mice to assess for differential miRNA expression in RAPCs after ischemic injury (30 minutes). Mouse RAPCs were isolated from renal arteries as previously described ${ }^{8}$ (Figure 2, A and B), immediately processed and submitted for miRNA microarray analysis. miRNA oligonucleotide probes were localized to 108 sequences specific for mmumiRNA (Figure 2C). Four mmu-miRNAs were downregulated and two were up-regulated in samples derived from animals undergoing ischemia compared to sham controls. тти-Mir218-5p expression displayed the largest mean decrease $(-1.89)$ among mature miRNAs and was of additional interest due to previous studies implicating the function of miR-218 in the vasculature. ${ }^{7}$ The fluorescence signal generated by mmu-Mir218-1-3p and mmu-Mir218-2$3 p$ probes did not reach the assigned minimum threshold and therefore were reported as not detected.

\section{MIR218-5p Expression in a Clinical Model of Ischemic Kidney Injury}

Human renal artery samples from patients who underwent radical nephrectomy for cancer therapy were studied prospectively $(n=58)$ to determine whether miR-218 detected in animals correlated with ischemic injury in humans. Mean warm ischemia time was $32.3 \pm 4.5$ minutes. MIR218 expression was detected using an oligonucleotide probe specific for mature MIR218-5p and then quantitated in histologic cross sections of the adventitial interstitium where RAPCs are known to reside ${ }^{8}$ (Figure $3 \mathrm{~A}$ ). $M I R 218^{+}$cells in the adventitial vasa vasorum of the renal artery were excluded from comparative analyses because of the complex architecture and heterogeneous cell populations expressing MIR2 18 therein. Patients with a decline in renal function of $\geq 10 \mathrm{~mL} /$ minute per $1.73 \mathrm{~m}^{2}$ had a higher overall mean expression of MIR218-5p $(P<0.001)$ (Figure 3B).

Sensitivity analysis identified patients with a relatively high ratio of adventitial MIR $218^{+}$cells/total cells at the time of surgery (ie, $\geq 0.12=M I R 218 \mathrm{Hi}$ ) to have an increased incidence of kidney function decline (Table 2) that occurred $696 \pm 516$ days after surgery compared to $803 \pm 610$ days in MIR218 Lo expressors $(P=0.63)$, with a risk for kidney function decline in MIR218 Hi that was durable through the end of the follow-up period (Figure 3C) $(P<0.05)$. A preoperative body mass index of $<30 \mathrm{~kg} / \mathrm{m}^{2}$, a Charlson comorbidity index of $<90 \%$, and a warm ischemia time of $\geq 31$ minutes also resulted in odds ratios that showed an absolute increase in risk (Table 2). MIR218 Hi patients had an increased warm ischemia time (34.4 versus 31.6 minutes, $P<0.01$ ) (Table 3).

Receiver operator characteristic curves were calculated to determine the sensitivity and specificity of MIR 218 expression, Charlson comorbidity index, 1/body mass index, and warm ischemia time to predict a decline in postoperative kidney function. The receiver operator characteristic curves of warm ischemia time and MIR218 expression were statistically significant (Figure 3D) (both, $P<0.01)$. MIR 218 outperformed warm ischemia time, with an area under the curve of $0.82(95 \% \mathrm{CI}, 0.67-0.91)$ versus an area under the curve of 0.70 (95\% CI, 0.57-0.84), respectively. Human results here suggest that miR-218-5p expression in RAPCs increases initially after mild ischemia, while the animal screen mentioned in the previous paragraph suggests a decline in miRNA expression after severe ischemic exposure. The discrepancy in the murine 


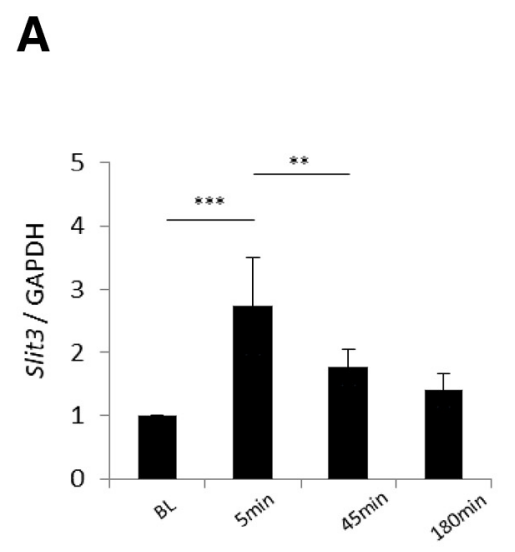

C

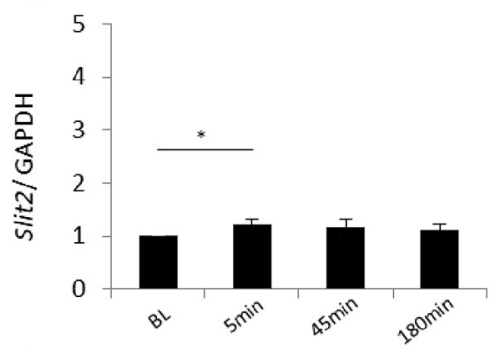

$\mathbf{F}$

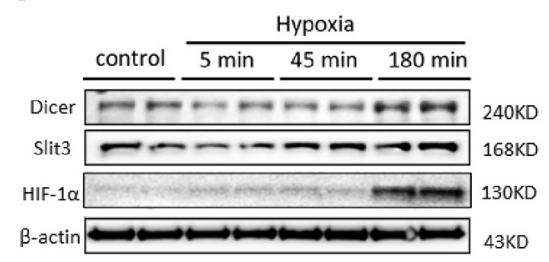

B

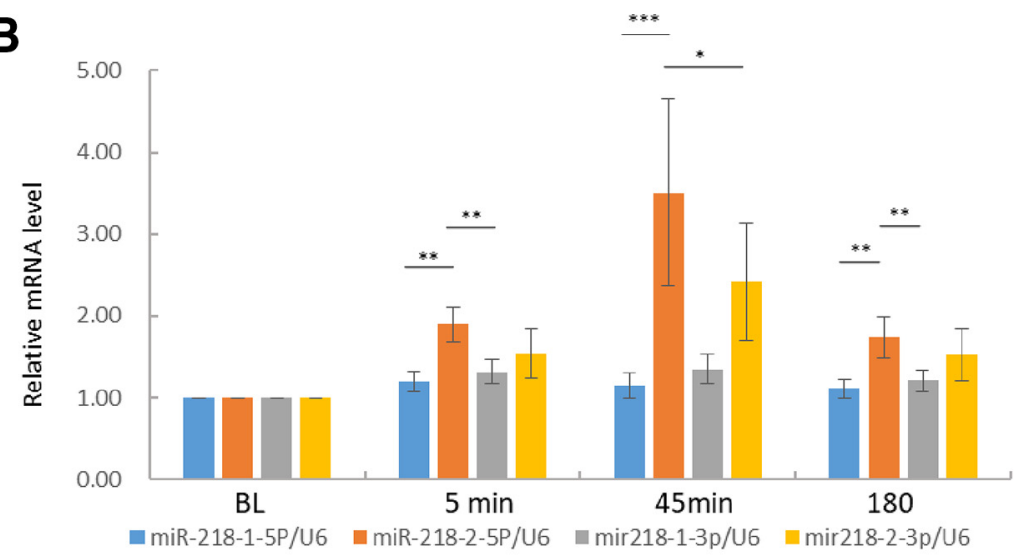

E
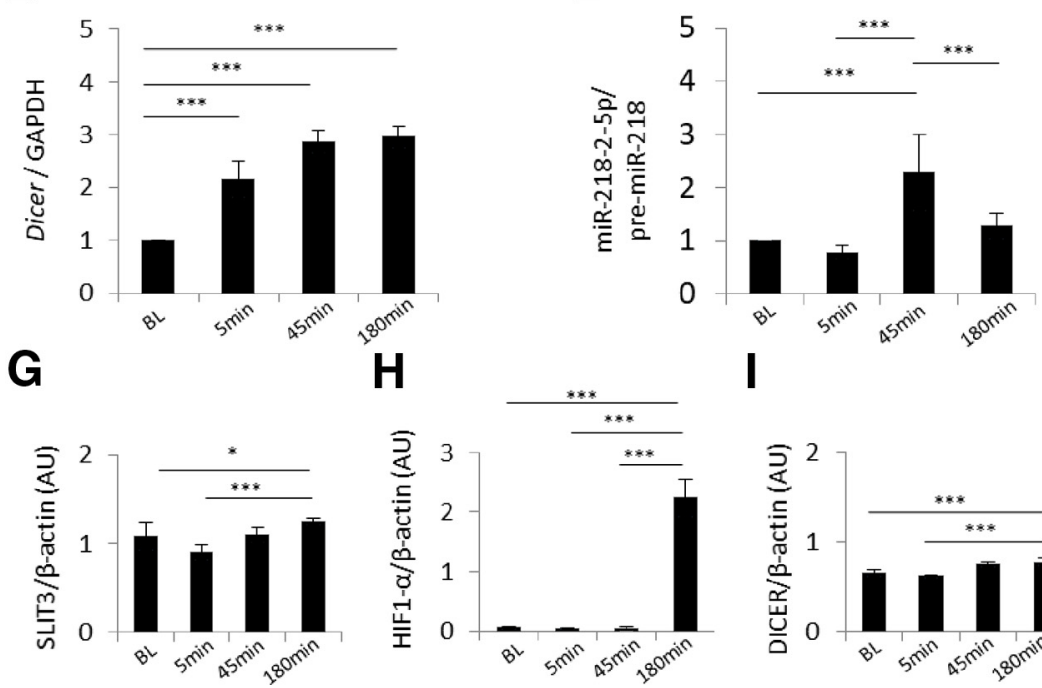

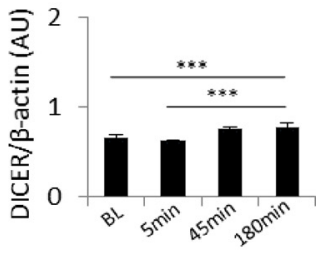

Figure 4 Slit guidance ligand host genes (SLIT), miR-218 expression and associated protein levels in renal artery-derived endothelial progenitor cells (EPCS) exposed to hypoxia. A: Relative SLIT3 expression at baseline versus 5 minutes of hypoxia and 5 versus 45 minutes of hypoxia. B: Comparison of miR218-1-5p, miR-218-2-5p, miR-218-1-3p, and miR-218-2-3p mRNA levels: miR-218-2-5p versus miR-218-1-5p at 5 minutes, miR-218-2-5p versus miR-218-1-3p at 5 minutes, miR-218-2-5p versus miR-218-1-5p at 45 minutes, miR-218-2-5p versus miR-218-2-3p at 45 minutes, miR-218-2-5p versus miR-218-1-5p at 180 minutes, and miR-218-2-5p versus miR-218-1-3p at 180 minutes. C: Relative SLIT2 expression at baseline versus 5 minutes of hypoxia. D: Relative Dicer expression at baseline versus 5, 45, and 180 minutes of hypoxia. E: Relative miR-218-2-5p/pre-miR-218 expression at baseline versus 45 minutes of hypoxia, 5 versus 45 minutes of hypoxia, and 45 versus 180 minutes of hypoxia. F: Representative immunoblot of intracellular protein from EPCS after hypoxia. G: SLIT3 protein levels relative to $\beta$-actin at baseline versus 180 minutes of hypoxia, and 5 versus 180 minutes of hypoxia. H: Hypoxia-inducible factor (HIF)-1 $\alpha$ protein levels relative to $\beta$-actin at baseline versus 180 minutes of hypoxia, 5 versus 180 minutes of hypoxia, and 45 versus 180 minutes of hypoxia. I: DICER protein levels relative to $\beta$-actin at baseline versus 180 minutes of hypoxia, and 5 versus 180 minutes of hypoxia. $n=10$ or 11 patients per group. ${ }^{\star} P<0.05$, ${ }^{* * P}<0.01$, and ${ }^{* *} P<0.001$. AU, arbitrary units; GAPDH, glyceraldehyde phosphate dehydrogenase.

and human screening tests warranted further investigation as to the dynamic expression of miR-218 in the renal vasculature.

\section{Mature MIR218 Expression in Isolated Endothelial Progenitor Cells}

Isolated human EPCs derived from renal arteries were placed in a hypoxic environment to more precisely understand the biomolecular context of mature miR-218 products and discern whether the miR-218-5p expression in the above human screening assays (MIR218-5p Expression in a Clinical Model of Ischemic Kidney Injury) derived from
miR-218-1 or miR-218-2. Because the deletion of the miR218-2 host gene, Slit3, is known to cause renal agenesis in mice, ${ }^{19}$ we chose to investigate the SLIT3/MIR218-2 expression axis further. EPCs were exposed to hypoxia for 5, 45 , and 180 minutes to assess the acute effects of hypoxia on mature miR-218 cleavage products and the SLIT3 host gene in cells of endothelial lineage in distinction to previous investigations of chronic hypoxia. ${ }^{20,21}$ SLIT3 mRNA was increased after 5 minutes of hypoxia (Figure 4A). SLIT3 protein concentration was increased after 180 minutes (Figure 4, F and G) after the earlier up-regulation of SLIT3 mRNA synthesis after 5 minutes of hypoxia (Figure 4A). Upregulation of the SLIT3 host gene suggested that miR-218-2 


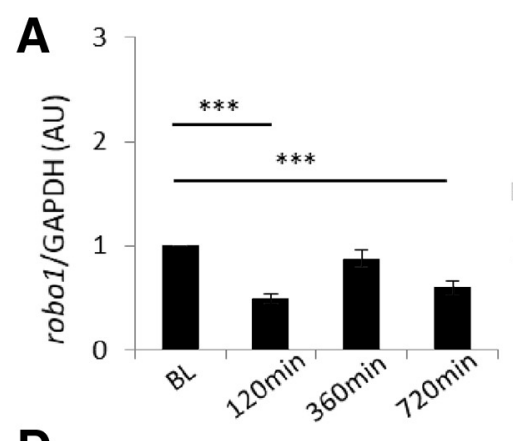

D
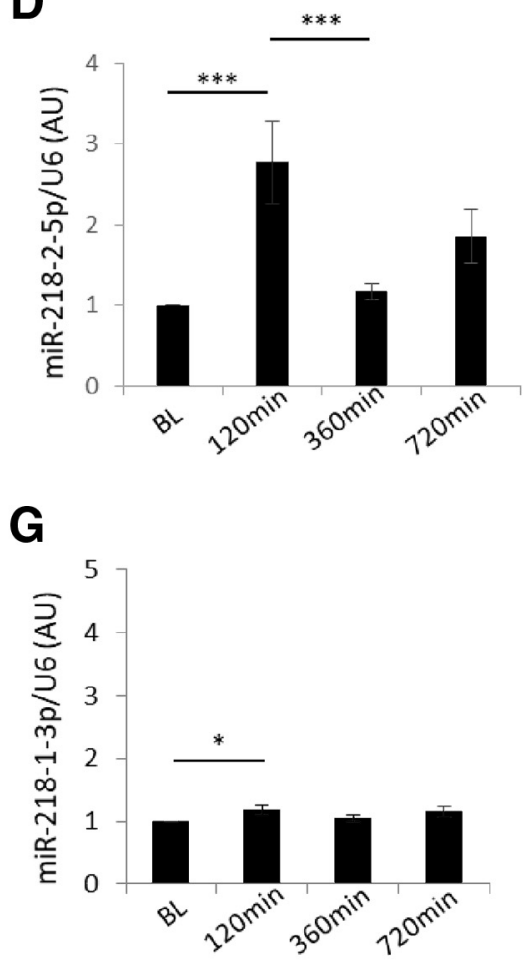

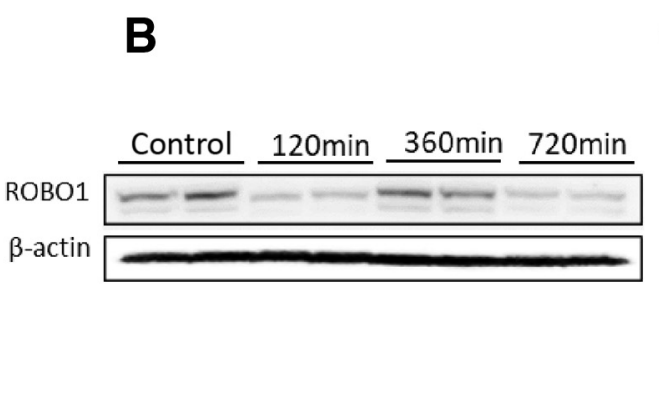

E

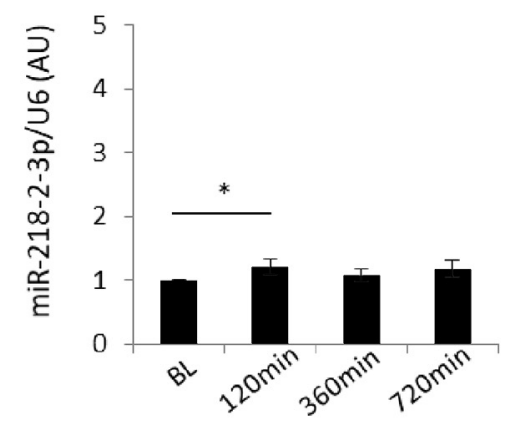

H

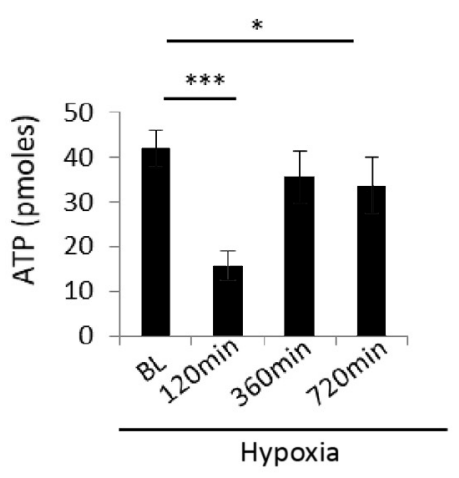

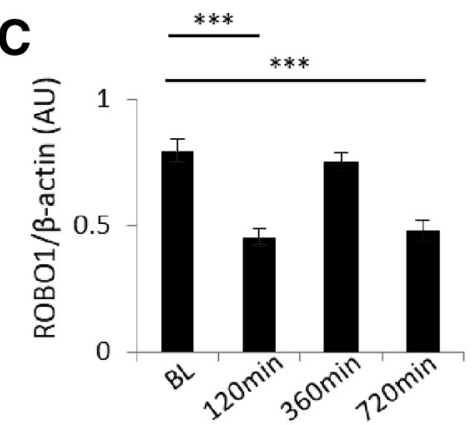

$\mathbf{F}$
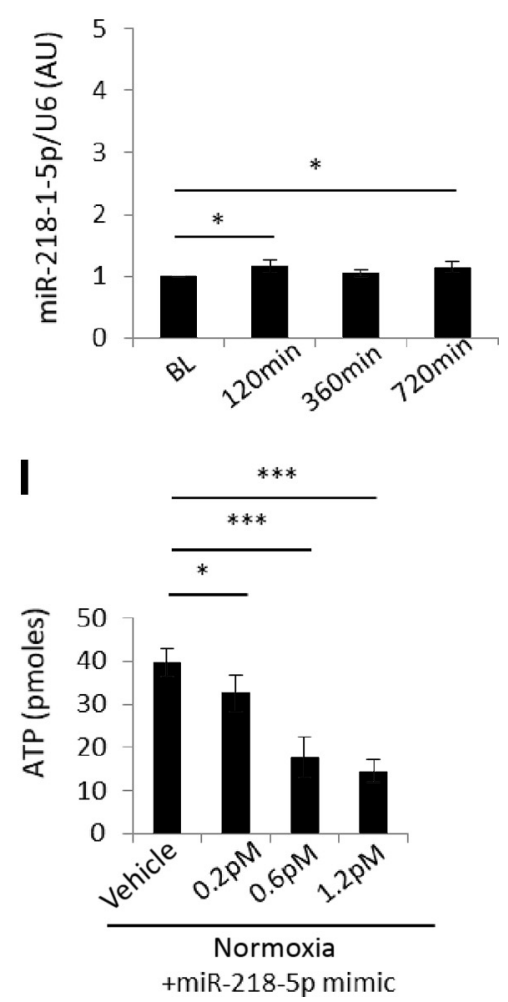

Figure 5 miR-218 expression and function in endothelial progenitor cells (EPCS) exposed to 30 minutes of hypoxia followed by a normoxic recovery period. A: Relative ROBO1 expression at baseline versus 120 minutes post-hypoxia, versus 720 minutes post-hypoxia. B: Representative immunoblot of intracellular roundabout guidance receptor (ROB0)-1 protein from EPC after 30 minutes hypoxia and subsequent normoxic incubation. C: R0B01 protein levels relative to $\beta$ actin at baseline versus 120 minutes post-hypoxia, versus 720 minutes post-hypoxia. D: Relative miR-218-2-5p expression at baseline versus 120 minutes post-hypoxia, and 120 versus 360 minutes post-hypoxia. E: Relative miR-218-2-3p expression at baseline versus 120 minutes post-hypoxia. F: Relative miR218-1-5p expression at baseline versus 120 minutes post-hypoxia, versus 720 minutes post-hypoxia. G: Relative miR-218-1-3p expression at baseline versus 120 minutes post-hypoxia. H: Intracellular ATP in cells after 30 minutes of hypoxia and subsequent normoxic incubation, baseline versus 120 minutes posthypoxia incubation, versus 720 minutes post-hypoxia incubation. I: Intracellular ATP in cells after treatment with MIR218-5p mimic, vehicle versus 0.2 , 0.6, and $1.2 \mathrm{pmol} / \mathrm{L}$ in normoxic conditions. ${ }^{*} P<0.05,{ }^{* *} P<0.001$. GAPDH, glyceraldehyde phosphate dehydrogenase.

was in turn up-regulated and then cleaved to form miR-218$2-5 p$ in EPCs with coordinated SLIT3 and miR-218 expression as previously reported in normoxic conditions. ${ }^{7}$

Mature miR-218-2-5p increased after 5 minutes of hypoxia and continued to increase after 45 minutes of hypoxia (Figure 4B). miR-218-1-5p and miR-218-1-3p expression were increased over the same time period but miR-218-2-5p increase was $29 \%$ greater than miR-218-1-5p after 5 minutes $(P<0.05)$ and $216 \%$ after 45 minutes $(P<0.001)$ (Figure 4B). miR-218-2-3p was increased compared to baseline (Figure 4B) despite not meeting the threshold for detection in initial miRNA microarray screens reported in the previous paragraph. miR-218-2-5p $(P<0.05)$ levels, however, were $45.0 \%$ greater than miR-218-2-3p after 45 minutes of hypoxia. After 5 minutes of hypoxia, the mRNA transcript of the miR-218-1 host gene, SLIT2, was increased $20.1 \%$ from baseline (Figure 4C) while SLIT3 transcript was increased $172 \%$ from baseline (Figure 4A). DICER transcript, encoding for a pre-miRNA endoribonuclease known to be functional in multiple mammalian kidney cell types $^{22-24}$ and affected by hypoxia, ${ }^{25}$ was also increased after 5 and 45 minutes of hypoxia (Figure 4D). This finding 

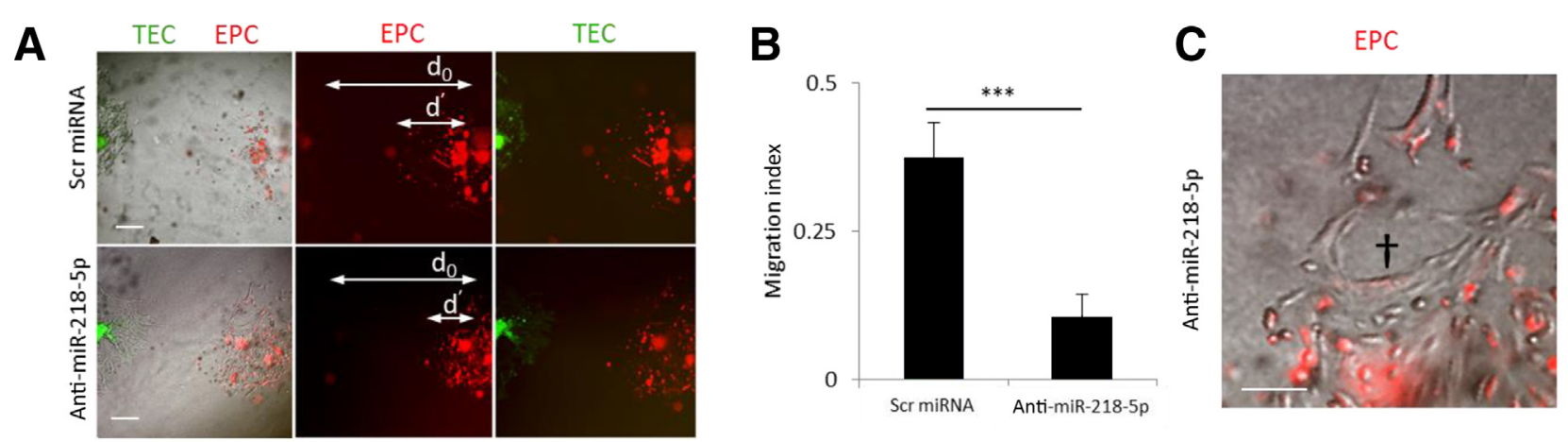

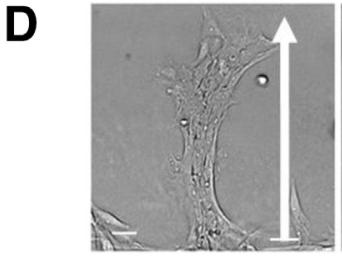

Scr miRNA

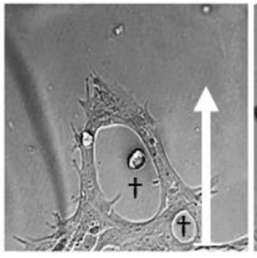

Anti-miR-218-5p

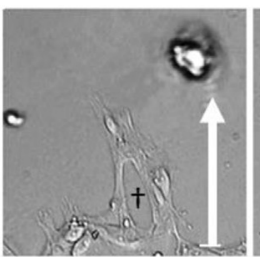

Anti-miR-218-2-3p

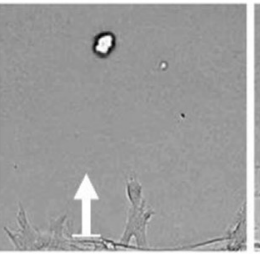

siRNA dicer

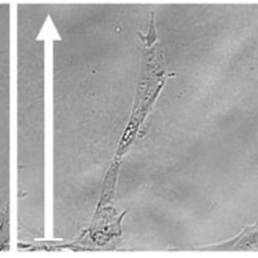

siRNA dicer+ mir218-5p mimic
$\mathbf{E}$

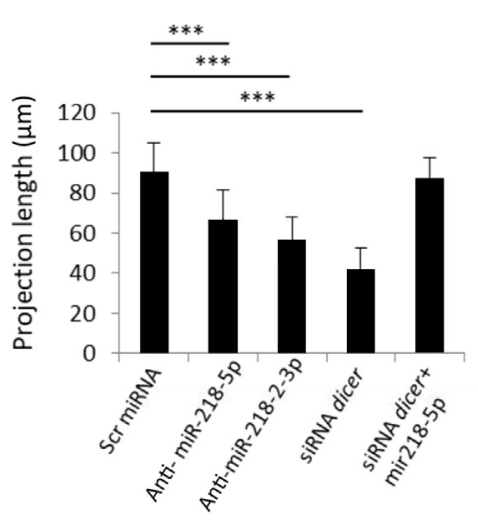

$\mathbf{F}$

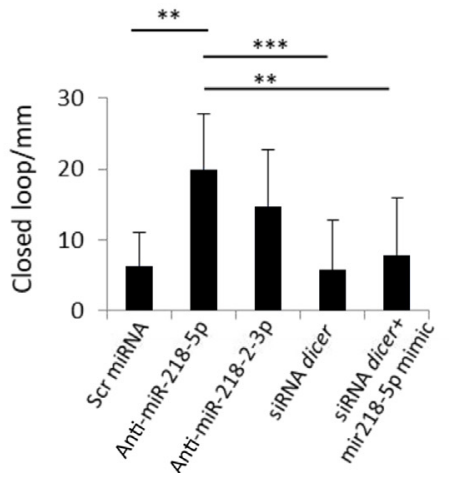

G

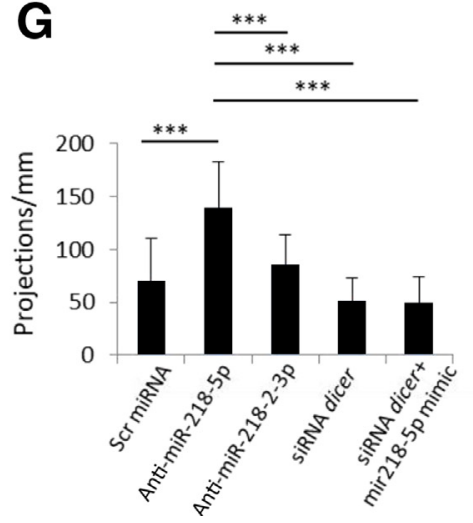

Figure 6 Renal artery-derived endothelial progenitor cell (EPC) growth characteristics in three-dimensional culture. A: Microscopic images of EPC migration pattern as labeled by CellTracker Red CM-Dil and tubular epithelial cells (TECs) labeled by CellTracker Green CMFDA in three-dimensional Matrigel culture after scramble $(\mathrm{Scr})$ miRNA or anti-MIR218-5p treatment. B: Migration index $\left(\mathrm{d}^{\prime} / \mathrm{d}_{0}\right)$ calculated after pretreatment of EPCs with scrambled miRNA or anti-MIR218-5p, respectively, from cells derived from seven separate patients. C: Premature capillary loops (dagger) formed by EPC pretreated with antiMIR218-5p. D: Representative microscopic images of organized cell projections (arrows indicate linear distance of projection) capillary loop (daggers). Patterns in three-dimensional Matrigel cultured EPC cells treated with scrambled miRNA control, or anti-MIR218-5p (50 nmol/L), or anti-MIR218-2-3p (50 $\mathrm{nmol} / \mathrm{L})$, or siRNA-DICER $(50 \mathrm{nmol} / \mathrm{L})$, or siRNA-DICER plus MIR218-5p mimic, after 48 hours of vascular endothelial growth factor stimulation. E: Cell projection length in scrambled miRNA controls versus anti-MIR218-5p transfected cells, versus anti-MIR218-2-3p transfected cells, versus siRNA-DICER transfected cells. F: Quantification of closed-loop number per millimeter in anti-MIR218-5p transfected cells versus scrambled miRNA controls, versus siRNA-DICER transfected cells, and versus siRNA-DICER + MIR18-5p-mimic transfected cells. G: Quantification of cell projection number per millimeter in anti-MIR218$5 p$-transfected cells versus scrambled miRNA controls versus anti-MIR218-2-3p-transfected cells versus siRNA-DICER-transfected cells versus siRNADICER + MIR218-5p-mimic transfected cells. ${ }^{* *} P<0.01,{ }^{*} * P<0.001 . n=7$ per group (B); $n=21$ per condition (D). Scale bars: $50 \mu \mathrm{mol} / \mathrm{L}$ (A); $25 \mu \mathrm{mol} /$ $L(C) ; 10 \mu \mathrm{mol} / L(\mathbf{D}) . d_{0}$, distance between leading edge of cells at time 0 ; $d^{\prime}$, distance between leading edge of EPC at 0 and 48 hours.

corresponded with a subsequent increase in DICER protein concentration after 180 minutes (Figure 4I). Furthermore, the ratio of mature $\mathrm{miR}-218-2-5 \mathrm{p} /$ pre-miR-218 was increased after 45 minutes of hypoxia (Figure 4E), suggesting DICER-dependent cleavage of miR-218-2 into mature miRNA. Consistent with the acuity of these cellular events, transcription levels of mRNA and miRNA described in the previous paragraph were all elevated prior to an increase in hypoxia-inducible factor $1 \alpha$, a known early marker of hypoxic injury (Figure 4, F and H). Finally, specificity of the expression mentioned in the previous paragraph to EPC was reflected in relatively decreased SLIT3 and miR-218-2$5 \mathrm{p}$ in human umbilical vein endothelial cells at the same time points (Supplemental Figure S3). In summary, miR218-2 was more acutely up-regulated after hypoxia compared to miR-218-1, and mature miR-218-2-5p was more highly expressed than miR-218-2-3p after 45 minutes of hypoxia.

EPCs were then exposed to 30 minutes of hypoxia followed by normoxia to simulate a recovery period in 

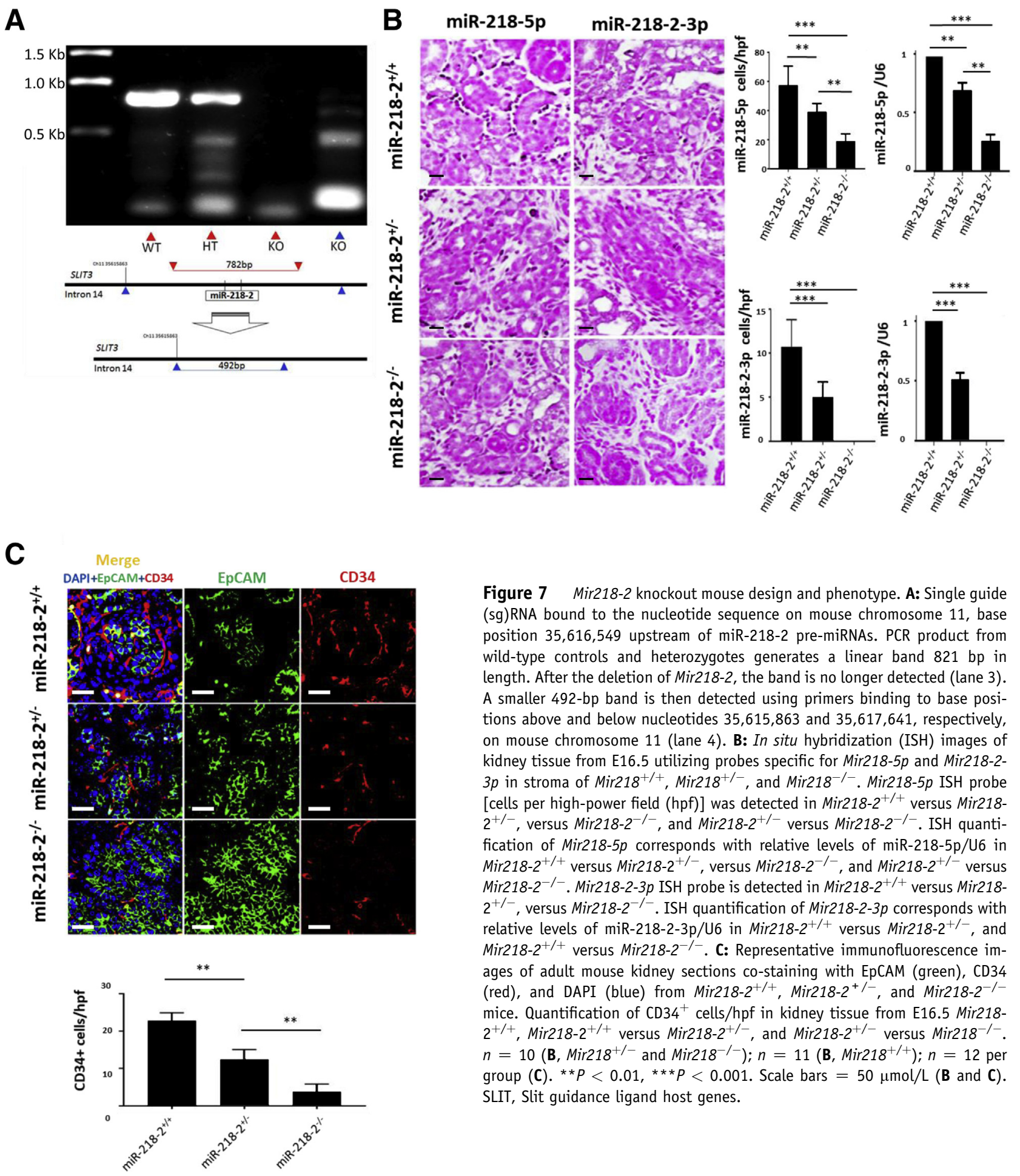

Figure 7 Mir218-2 knockout mouse design and phenotype. A: Single guide $(\mathrm{sg})$ RNA bound to the nucleotide sequence on mouse chromosome 11, base position 35,616,549 upstream of miR-218-2 pre-miRNAs. PCR product from wild-type controls and heterozygotes generates a linear band $821 \mathrm{bp}$ in length. After the deletion of Mir218-2, the band is no longer detected (lane 3). A smaller 492-bp band is then detected using primers binding to base positions above and below nucleotides $35,615,863$ and $35,617,641$, respectively, on mouse chromosome 11 (lane 4). B: In situ hybridization (ISH) images of kidney tissue from E16.5 utilizing probes specific for Mir218-5p and Mir218-2$3 p$ in stroma of Mir218 $8^{+/}$, Mir218 $^{+/-}$, and Mir218 ${ }^{-/-}$. Mir218-5p ISH probe [cells per high-power field (hpf)] was detected in Mir218-2 ${ }^{+/+}$versus Mir218$2^{+/-}$, versus Mir218-2 $2^{-/}$, and Mir218-2 $2^{+/-}$versus Mir218-2 ${ }^{-/-}$. ISH quantification of Mir218-5p corresponds with relative levels of miR-218-5p/U6 in Mir218-2 $2^{+/+}$versus Mir218-2 $2^{+/-}$, versus Mir218-2 ${ }^{-/}$, and Mir218-2 ${ }^{+/-}$versus Mir218-2 ${ }^{-/}$. Mir218-2-3p ISH probe is detected in Mir218-2 $2^{+/+}$versus Mir218$2^{+/-}$, versus Mir218-2 $2^{-/-}$. ISH quantification of Mir218-2-3p corresponds with relative levels of miR-218-2-3p/U6 in Mir218-2 $2^{+/+}$versus Mir218-2 $2^{+/-}$, and Mir218-2 $2^{+/+}$versus Mir218-2 ${ }^{-/-}$. C: Representative immunofluorescence images of adult mouse kidney sections co-staining with EpCAM (green), CD34 (red), and DAPI (blue) from Mir218-2 $2^{+/}$, Mir218-2 ${ }^{+/-}$, and Mir218-2 $2^{-/-}$ mice. Quantification of $\mathrm{CD}^{+} 4^{+}$cells/hpf in kidney tissue from E16.5 Mir218-

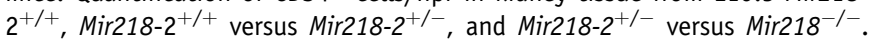

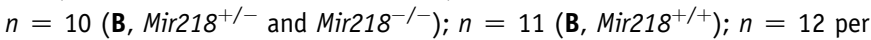
group (C). ${ }^{* *} P<0.01,{ }^{* * *} P<0.001$. Scale bars $=50 \mu \mathrm{mol} / \mathrm{L}$ (B and $\mathbf{C}$ ). SLIT, Slit guidance ligand host genes.

which endothelial cell migration programs are most likely active in the clinical setting. Due to an increase in miR218-2-5p expression observed between 5 and 45 minutes of hypoxia in the experiments mentioned in the prevoious paragraph, a 30 minutes hypoxia period was further justified. ROBOl mRNA transcript is a known target of miR-218 which promotes directed migration after denudation of endothelial progenitor and differentiated endothelial cells and therefore was measured after hypoxia $^{7,8}$ in sequence with a normoxic recovery period. Both ROBOl mRNA and ROBO1 protein expression were decreased after 120 minutes and increased after $360 \mathrm{mi}-$ nutes (Figure 5, A and B). ROBOI mRNA and ROBO1 protein levels followed a reciprocal pattern to miR-218-2$5 p$ expression in EPC after 120 and 360 minutes of normoxia (Figure 5, A-D), whereas miR-218-2-3p, miR-218- 

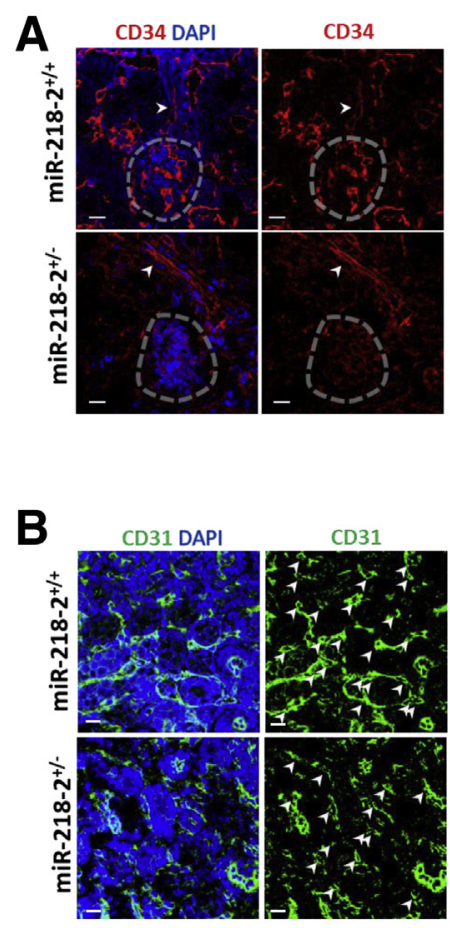
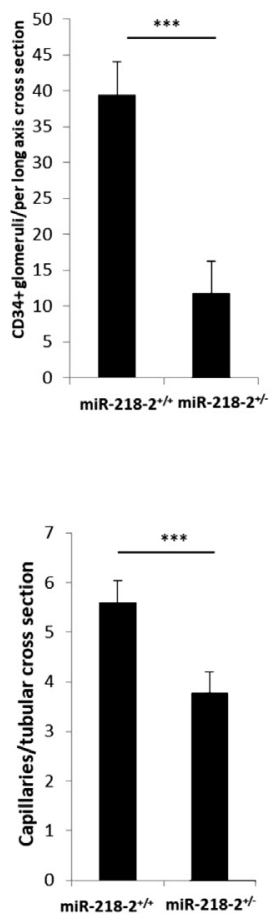

C

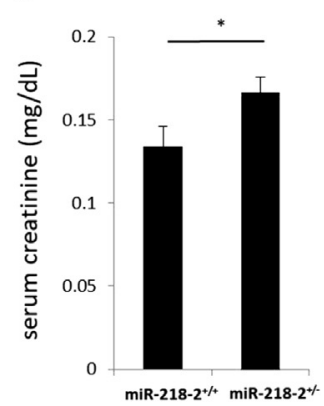

Figure 8 Functional analysis of Mir218-2 $2^{+/-}$at baseline. A: Representative microscopic images of kidney glomerular cross sections (dashed circles) with $>50 \% \mathrm{CD}^{+} 4^{+}$on neonatal day 1 in Mir218-2 $2^{+/+}$ versus Mir218-2 $2^{+/-}$(arrows indicate arterioles). B: Representative microscopic images of peritubular capillary cross sections (arrows) stained with $\mathrm{CD} 1^{+}$and DAPI in 14-day-old Mir218-2 $2^{+/-}$versus Mir218-2 $2^{+/+}$. C: Baseline serum creatinine levels in Mir218-2 $2^{+/-}$versus Mir218-2 $2^{+/+} . n=8$ (C, Mir218$\left.2^{+/+}\right) ; n=9\left(\mathbf{C}\right.$, Mir218-2 $\left.2^{+/-}\right) ; n=11$ per group $(\mathbf{A}) ; n=13\left(\mathbf{B}\right.$, Mir218-2 $\left.2^{+/+}\right) ; n=14$ (B, Mir218$\left.2^{+/-}\right) .{ }^{*} P<0.05,{ }^{* * *} P<0.001$. Scale bars: 50 $\mu \mathrm{mol} / \mathrm{L}(\mathbf{A}) ; 25 \mu \mathrm{mol} / \mathrm{L}(\mathbf{B})$. 1-5p, and miR-218-1-3p were increased modestly (Figure 5, E-G). A reduced catabolic state associated with nonmigratory cells was reflected in a decrease in ATP levels 120 minutes after hypoxia (Figure 5H). A subsequent increase in $R O B O 1 \mathrm{mRNA}$ and $\mathrm{ROBO} 1$ protein levels corresponded with an increase in ATP after 360 minutes. EPC transfected with miR-218-5p mimic, not exposed to hypoxia, contained relatively lower ATP concentrations compared to vehicle controls (Figure 5I). The decrease in ATP levels was similar to EPC exposed to hypoxia followed by normoxia. These results suggest a decreased metabolic rate can be recapitulated with miR218-5p mimic independent of the hypoxic environment.

\section{Mature miR-218 Function in Isolated Endothelial Progenitor Cells}

The physiologic effect of mature MIR218-5p up-regulation in human EPCs was initially assessed with cell motility assays using human proximal TECs as a source of VEGF to simulate the physiologic paracrine interactions between these two cell types in the kidney. ${ }^{26}$ We identified a decrease in migration toward TECs when EPCs were pretreated with anti-miR-218-5p (Figure 6, A and B). However, EPCs were also observed to develop premature capillary loops (Figure 6C), which was distinct from the accelerated linear growth previously reported when pretreating a monolayer of RAPCs with anti-miR-218 in cell-denudation studies (ie, streak testing). ${ }^{7,8}$ To better understand why miR218-5p inhibition was associated with contrasting motility results, EPCs were then interrogated in isolation.
Recognizing that miR-218-2 is cleaved to form mature miR218-5p and miR-218-2-3p, cells were separately transfected with anti-MIR218-5p and anti-MIR218-2-3p (Figure 6D). Linear projection length was decreased in anti-MIR218-5p and anti-MIR218-2-3p treated cells (Figure 6E). Anti-MIR218-5p treated EPCs demonstrated a less organized response to VEGF stimulation in three-dimensional culture by forming closed loops more frequently detected than in control conditions (Figure 6F). Treatment with anti$-M I R 218-3 p(P<0.001)$ promoted fewer capillary projections per millimeter than did anti-MIR218-2-5p (Figure 6G). Cells transfected with DICER siRNA (Supplemental Figure S1) in Matrigel formed unstable cell projections. Cells co-transfected with miR-218-5p mimic (0.2 pmol/L) and DICER siRNA showed increase cell projection length compared to anti-miR-treated and DICER siRNA-treated colonies (Figure 6, B-D). Taken together these in vitro experiments showed that EPCs derived from kidney vasculature preferentially expressed miR-218-2-5p, a binding partner of $R O B O 1$ transcript, after hypoxia while miR-218-5p modulated EPC motility.

\section{Susceptibility of Mir218 Knockout Model to Ischemic Injury}

SLIT3 transcription and SLIT3 protein expression were upregulated along with miR-218-2 in EPCs after hypoxia. This observation aligned with the concept of a miRNA host gene described by other groups. ${ }^{7,27}$ We therefore rapidly constructed a genetically engineered animal model using CRISPR technology to test the hypothesis that endogenous 

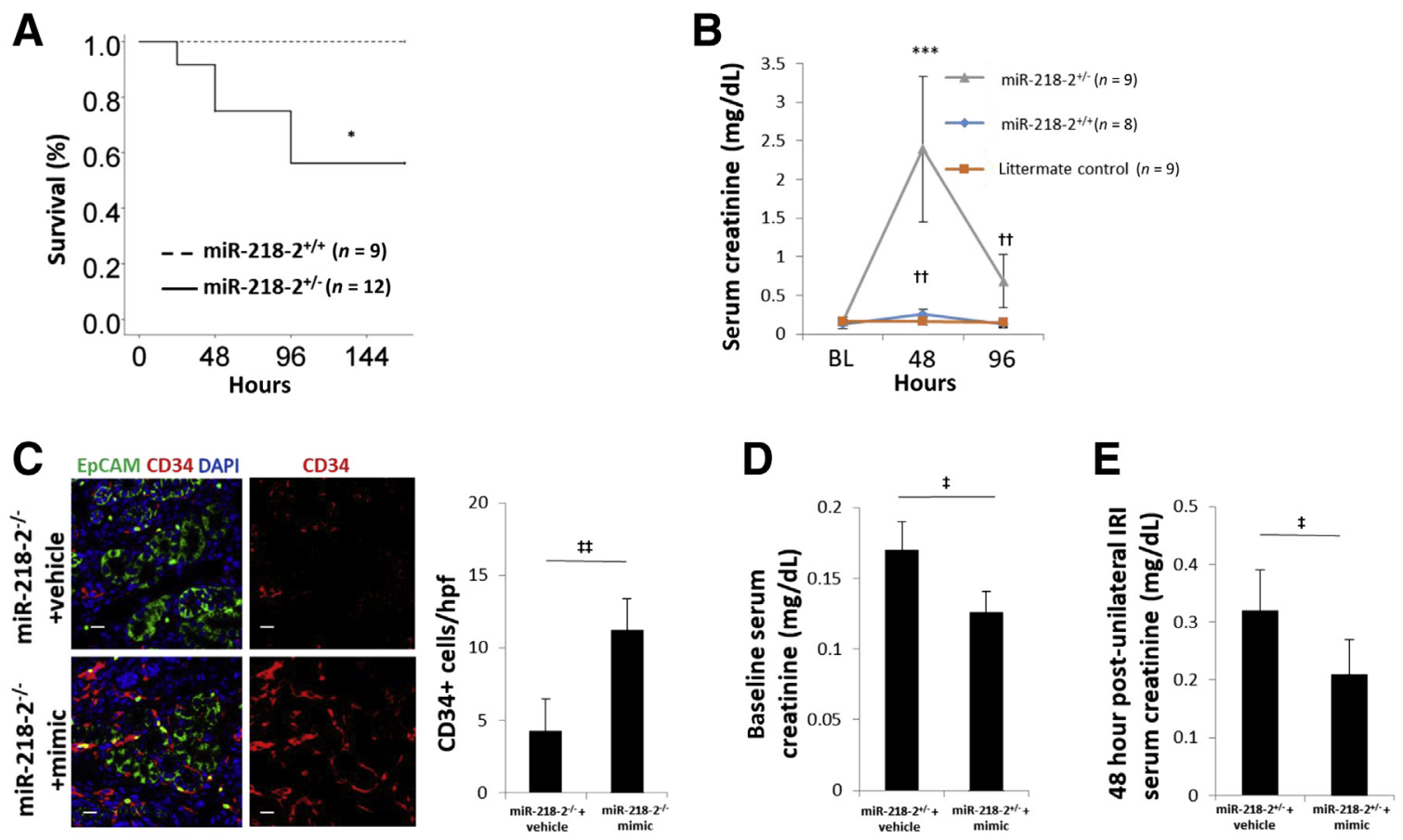

Figure 9 Functional analysis of Mir218-2 $2^{+/-}$after kidney injury and treatment. A: Kaplan-Meier survival curve analysis of adult mice that underwent ischemia/reperfusion injury (IRI), Mir218-2 $2^{+/-}$versus Mir218-2 $2^{+/+}$. B: Time course of serum creatinine levels after IRI in Mir218-2 $2^{+/-}$versus Mir218-2 $2^{+/+}$, at 48 hours, Mir218-2 $2^{+/+}$versus littermate control and 96 hours. C: Representative immunofluorescence images of knockout mice co-staining with EpCAM (green), CD34 (red), and DAPI (blue) in Mir218-2 $2^{-1-}+$ vehicle versus Mir218-2 ${ }^{-1-}+$ mimic. D: Baseline serum creatinine in adult Mir218-2 $2^{+/-}$animals are previously given scrambled miRNA (vehicle) versus miR-218-5p mimic (mimic) in utero. E: Serum creatinine in Mir218-2 ${ }^{+/-}$adults 48 hours after unilateral IRI and injection of scrambled miRNA (vehicle) versus miR-218-5p mimic, respectively. $n=9\left(\mathbf{A}\right.$, Mir218-2 $\left.2^{+/+} ; \mathbf{B}\right) ; n=12\left(\mathbf{A}, M^{\text {Mir } 218-2^{+/-}}\right) .{ }^{*} P<0.05,{ }^{* * *} P<$ 0.001 versus miR218-2 $2^{+/+} ;{ }^{\dagger \dagger} P<0.01$ miR218-2 $2^{+/+}+$IRI versus miiR218-2 $2^{+/+}+$sham; ${ }^{\ddagger} P<0.05,{ }^{\ddagger \ddagger} P<0.01$. Scale bars $=50 \mu \mathrm{mol} / \mathrm{L}$.

miR-218 expression in mammalian kidney vasculature plays a vital physiologic role in the setting of hypoxia. Resultant data from the animal model would potentially have greater clinical relevance due to endogenous miR-218 expression identified in miR-218-5p Expression in a Clinical Model of Ischemic Kidney Injury in parallel human renal vascular structures.

The mouse model contained a germline deletion that resulted in the removal of $1.23 \mathrm{Kbp}$ from intron 14 of the Slit3 gene on chromosome 11 of all homozygous offspring (Figure 7A). Mir218-2 $2^{-/-}$cells underwent partial gestational development but were nonviable. ISH was used to identify Mir218-5p and Mir218-2-3p in the nephrogenic interstitium and stroma in E16.5 littermate controls. The specificity of Mir218-2 deletion was supported by a decrease

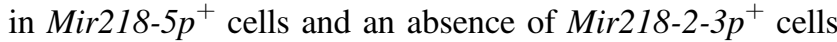
detected by ISH. This finding was confirmed by quantitative PCR measures of Mir218-5p and Mir218-2-3p in Mir218$2^{-l-}$ embryos and littermate controls (Figure 7B). On E16.5 the ureteric bud contained a relatively decreased number of $\mathrm{CD}_{4} 4^{+}$angioblasts compared to littermate controls (Figure 7C). Among Mir218-2 $2^{+/-}$neonates that survived, there was a decreased number of glomeruli containing $\mathrm{CD}^{+} 4^{+}$cells at postnatal day 1 (Figure $8 \mathrm{~A}$ ) and decreased capillary density quantifiable on postnatal day 14 (Figure 8B). Retinal tissue from 12-week-old Mir218-2 ${ }^{+/-}$ animals was assessed to determine the significance of the germline deletion on other vascular beds where miR-218 is known to have a functional role. ${ }^{7}$ No difference in retinal capillary density was identified between heterozygotes and littermate controls (Supplemental Figure S4). However, serum creatinine was elevated at baseline in adult heterozygotes (Figure $8 \mathrm{C}$ ). Furthermore, mortality was increased at 96 hours after the standard 30-minute kidney-specific IRI compared to that in littermate controls (Figure 9A). After 48 hours, serum creatinine level in Mir218-2 ${ }^{+/-}$animals undergoing IRI were 9.3-fold higher than that in littermate control animals undergoing IRI (Figure 9B). Serum creatinine levels in Mir218-2 $2^{+/-}$animals remained elevated after 96 hours. The specificity of miR-218 function in the kidney was assessed after injection of miR-218-5p mimic into pregnant Mir218-2 $2^{+/-}$sired by Mir218-2 $2^{+/-}$males. On E16.5 the ureteric bud in Mir218-2 $2^{-1-}$ embryos showed CD34+ angioblast cell density that was increased compared to that in Mir218-2 $2^{-1-}$ embryos whose mothers received vehicle (Figure 9C). Baseline serum creatinine of surviving Mir218-2 $2^{+l}$ adults undergoing embryonic injection was decreased compared to that in animals with scrambled miRNA injected into a pregnant Mir218-2 $2^{+/-}$animal (Figure 9D). Mir218-2 $+/-$ adults undergoing unilateral IRI and treated with mimic 6 hours after injury showed improved serum creatinine after 48 hours compared to that 
in animals that underwent the same injury given vehicle (Figure 9E).

The preclinical model of ischemic kidney injury mentioned in the previoius paragraph suggests that miRNA-218-2 expression is important in the normal development and repair of mammalian renal microvasculature of the animals studied. Furthermore, it supports the above in vitro studies (Mature MIR218 Expression in Isolated Endothelial Progenitor Cells) that show that the expression of mature miRNA miR-218-2-5p is responsive to hypoxia in human vasculature derived from the kidney.

\section{Discussion}

We screened for cellular programs controlled by miRNA that may contribute to injury and/or repair in the kidney and found that miR-218 responded to hypoxia in both mouse and human models (Figures 2 and 3). miRNA profiles have been associated with the progression of diabetic nephropathy ${ }^{28,29}$ and chronic kidney disease in general ${ }^{30}$ but have yet to elucidate the role of miR-218 in any type or subtype of progressive kidney disease. miR-218 expression in kidney development and injury-induced hypoxia is shown here to be crucial for capillary function with potentially widereaching implications to other organ systems where endothelial cells are exposed to hypoxic conditions.

Investigation of molecular signaling in these preclinical models was informed by previous reports describing the crucial role of microRNA in the vascular system and embryonic kidney. ${ }^{22,31,32}$ The crucial role of miR-218-5p in the low oxygen state of embryonic development was reflected in the decreased number of angioblasts in the ureteric bud at E16.5 in animals with a homozygous deletion of Mir218-2 (Figure 7C). miR-218 expression in the placenta after delivery is known to be associated with hypoxia due to preeclampsia, although it is unclear whether pre-eclampsia is related to miR-218-1 or miR-218-2 up-regulation. ${ }^{33}$ In contrast, we demonstrated that miR-218$5 p$ and miR-218-2-3p are expressed in the developing kidney and that the absence of miR-218-2 expression was injurious to kidney development due to decreased capillary matrix formation in animals that reach full gestation (Figure 8B).

Results in human and mouse models demonstrated the complexity of miR-218 expression and function in the setting of hypoxia. Expression patterning was more fully elucidated in experiments in which EPCs underwent short hypoxia in isolation. In vitro experiments simulated the short warm ischemic injury of the initial screening experiments. Often such in vitro experiments reported by other groups exposed endothelial cells to between 6 and 24 hours of hypoxia, but such long periods of hypoxia do not simulate clinical warm ischemia, which often occurs in $<60$ minutes. ${ }^{33-37}$ After 30 minutes of warm ischemia in patients undergoing radical nephrectomy, we observed a subpopulation that had an increase in miR-218 expression (miR-218 $\mathrm{Hi}$ ) and a relative increase in warm ischemia time (Table 2).
Results paralleled in vitro experiments in which miR-218 expression continued to increase after 45 minutes of hypoxia (Figure 4B). miR-218 has been shown to inhibit the downstream effects of hypoxia-inducible factor $1 \alpha$ in a noncancerous model. ${ }^{38}$ We added to this concept by demonstrating the acute response of miR-218 to hypoxiainduced EPC injury prior to the accumulation of hypoxiainducible factor $1 \alpha$ protein (Figure $4 \mathrm{~F}$ ). Investigations showed that miR-218-5p and miR-218-2-3p expression in EPCs prefaced both an increase in hypoxia-inducible factor $1 \alpha$ and Slit3 protein concentration. Slit3 protein was increased after 45 minutes of hypoxia and coincided with increased Dicer concentrations. SLIT3 expression has been studied after longer durations of hypoxia, ${ }^{21}$ while DICER has been shown to decrease after 24 hours. DICER and SLIT3 protein expression patterns in endothelial cells after short durations of hypoxia ( $<60$ minutes) was not previously known. ${ }^{20,25}$ By identifying an up-regulation in MIR218-2-3p we further confirmed that miR-218-2 was involved in the human EPC response to acute hypoxia. This initial clinical screen, therefore, was supported by early expression patterns of hypoxia-induced molecular signals over a clinically relevant time period. A relative decrease in MIR218 expression after 3 hours paralleled results of severe ischemic injury represented by the initial murine miRNA microarray results (Figure 4A).

miR-218-5p expression in RAPCs is known to play an important role in cell signals that contribute to cell migration. ${ }^{7,8}$ This study, therefore, investigated the function of miR-218-5p compared to miR-218-2-3p in vitro to determine the relevance of miR-218-2 effector expression in human capillary formation when influenced by hypoxia. miR-218-2-5p and miR-218-2-3p are located in intron 14 of SLIT3. Slit3 deletion is known to cause renal agenesis in mice but had not been investigated in human preclinical models. ${ }^{19}$ In vitro studies showed SLIT3, MIR218-2-5p, and MIR218-2-3p were all up-regulated after brief exposures to hypoxia and corresponded with a decrease in ROBO1 protein expression within 2 hours of these transcriptional events (Figure 5). Furthermore, the inhibition of miR-218-5p in human EPCs was associated with short endothelial projections compared to those in controls (Figure 6). When miR-218-5p expression was reconstituted at relatively low concentrations, cell projection length increased in three-dimensional culture. This finding suggests that the endothelial migratory phenotype requires a modulated expression of miR-218-2 to achieve directional cell growth. The migration of RAPCs was enhanced by miR-218 inhibition but did not characterize capillary development. ${ }^{8}$ The isolated reconstitution of mature miR218-5p with Dicer siRNA suggested a specific effect of miR-218 over other miRNA cleaved by DICER in the setting of capillary loop formation. miR-218-2-3p inhibition in vitro also retarded formation, although this mature miRNA was not as highly expressed as miR-218-2-5p during hypoxia. The physiologic setting and stimulus that 
up-regulates miR-218-2-3p in EPCs derived from the kidney remain unclear.

Timed injection of miR-218-5p in pregnant Mir218-2 $2^{+/-}$ and nonpregnant adults emphasized the effect of miR-218-2 in the formation and repair of kidney microcapillaries, respectively. The persistent effect of mimic injection in offspring was demonstrated by the improvement in serum creatinine in 12-week-old Mir218-2 $2^{+/-}$adults that received mimic in utero (Figure 9D). Injection of mimic in Mir218$2^{+/-}$adults after IRI followed by improvement in serum creatinine 48 hours after injury inferred the relevance of miR-218 in kidney repair (Figure 9E).

There were important limitations to this investigation that deserve mention. First, the murine miRNA did not align with previous results from Godwin et $\mathrm{al}^{39}$ in the setting of ischemic kidney injury. These disparate results may be explained by the multitude of cell types found in whole kidney digestion 24 hours after ischemic kidney injury and infer separate cellspecific miRNA programs within the kidney after hypoxia. Second, miR-218 is known to be expressed in non-EPC types. Conditional knockout experiments are needed for isolating the function of this miRNA in organ systems in which its function may be more crucial due to a lack of redundant cell types that transcribe and cleave miR-218 to its mature forms.

\section{Conclusions}

We describe miR-218-2 as an important regulator of vascular development and hypoxic response in $\mathrm{CD} 34^{+}$ EPCs. These findings have the potential to provide crucial information that can anticipate renal function decline after ischemia. Further investigations should explore the therapeutic options of kidney-derived $\mathrm{CD} 34^{+} / \mathrm{CD} 105^{-}$in the setting of ischemic microcapillary injury.

\section{Supplemental Data}

Supplemental material for this article can be found at http://doi.org/10.1016/j.ajpath.2019.11.014.

\section{References}

1. Chertow GM, Burdick E, Honour M, Bonventre JV, Bates DW: Acute kidney injury, mortality, length of stay, and costs in hospitalized patients. J Am Soc Nephrol 2005, 16:3365-3370

2. Best PJ, Lennon R, Ting HH, Bell MR, Rihal CS, Holmes DR, Berger PB: The impact of renal insufficiency on clinical outcomes in patients undergoing percutaneous coronary interventions. J Am Coll Cardiol 2002, 39:1113-1119

3. Siedlecki A, Irish W, Brennan DC: Delayed graft function in the kidney transplant. Am J Transplant 2011, 11:2279-2296

4. Kramann R, Tanaka M, Humphreys BD: Fluorescence microangiography for quantitative assessment of peritubular capillary changes after AKI in mice. J Am Soc Nephrol 2014, 25:1924-1931

5. Venkatachalam MA, Weinberg JM, Kriz W, Bidani AK: Failed tubule recovery, AKI-CKD transition, and kidney disease progression. J Am Soc Nephrol 2015, 26:1765-1776
6. Sinclair RA: Origin of endothelium in human renal allografts. Br Med J 1972, 4:15-16

7. Small EM, Sutherland LB, Rajagopalan KN, Wang S, Olson EN: MicroRNA-218 regulates vascular patterning by modulation of SlitRobo signaling. Circ Res 2010, 107:1336-1344

8. Pang P, Abbott M, Chang SL, Abdi M, Chauhan N, Mistri M, Ghofrani J, Fucci QA, Walker C, Leonardi C, Grady S, Halim A, Hoffman R, Lu T, Cao H, Tullius SG, Malek S, Kumar S, Steele G, Kibel A, Freedman BS, Waikar SS, Siedlecki AM: Human vascular progenitor cells derived from renal arteries are endothelial-like and assist in the repair of injured renal capillary networks. Kidney Int 2017, 91:129-143

9. Pan L, Lian W, Zhang X, Han S, Cao C, Li X, Li M: Human circular RNA0054633 regulates high glucose-induced vascular endothelial cell dysfunction through the microRNA218/roundabout 1 and microRNA218/heme oxygenase1 axes. Int $\mathrm{J}$ Mol Med 2018, 42: 597-606

10. Zhao XC, Zhang LM, Li Q, Tong DY, Fan LC, An P, Wu XY, Chen WM, Zhao P, Wang J: Isoflurane post-conditioning protects primary cultures of cortical neurons against oxygen and glucose deprivation injury via upregulation of Slit2/Robo1. Brain Res 2013, 1537:283-289

11. Siedlecki AM, Jin X, Thomas W, Hruska KA, Muslin AJ: RGS4, a GTPase activator, improves renal function in ischemia-reperfusion injury. Kidney Int 2011, 80:263-271

12. Wang B, Xi Y: Challenges for microRNA microarray data analysis. Microarrays (Basel) 2013, 2:34-50

13. Reiner A, Yekutieli D, Benjamini Y: Identifying differentially expressed genes using false discovery rate controlling procedures. Bioinformatics 2003, 19:368-375

14. Pang $\mathrm{P}$, Jin $\mathrm{X}$, Proctor BM, Farley M, Roy N, Chin MS, von Andrian UH, Vollmann E, Perro M, Hoffman RJ, Chung J, Chauhan N, Mistri M, Muslin AJ, Bonventre JV, Siedlecki AM: RGS4 inhibits angiotensin II signaling and macrophage localization during renal reperfusion injury independent of vasospasm. Kidney Int 2015, 87:771-783

15. Modification of Diet in Renal Disease Study Group: The modification of diet in renal disease study: design, methods, and results from the feasibility study. Am J Kidney Dis 1992, 20:18-33

16. Chade AR, Zhu X, Lavi R, Krier JD, Pislaru S, Simari RD, Napoli C, Lerman A, Lerman LO: Endothelial progenitor cells restore renal function in chronic experimental renovascular disease. Circulation 2009, 119:547-557

17. Schmittgen TD, Lee EJ, Jiang J, Sarkar A, Yang L, Elton TS, Chen C: Real-time PCR quantification of precursor and mature microRNA. Methods 2008, 44:31-38

18. Yokoyama M, Fujii Y, Takeshita H, Kawamura N, Nakayama T, Iimura Y, Sakura M, Ishioka J, Saito K, Koga F, Masuda H, Noro A, Arisawa C, Kitahara S, Kihara K: Renal function after radical nephrectomy: development and validation of predictive models in Japanese patients. Int J Urol 2014, 21:238-242

19. Liu J, Zhang L, Wang D, Shen H, Jiang M, Mei P, Hayden PS, Sedor JR, Hu H: Congenital diaphragmatic hernia, kidney agenesis and cardiac defects associated with Slit3-deficiency in mice. Mech Dev 2003, 120:1059-1070

20. Ho JJ, Metcalf JL, Yan MS, Turgeon PJ, Wang JJ, Chalsev M, Petruzziello-Pellegrini TN, Tsui AK, He JZ, Dhamko H, Man HS, Robb GB, Teh BT, Ohh M, Marsden PA: Functional importance of Dicer protein in the adaptive cellular response to hypoxia. J Biol Chem 2012, 287:29003-29020

21. Liao WX, Laurent LC, Agent S, Hodges J, Chen DB: Human placental expression of SLIT/ROBO signaling cues: effects of preeclampsia and hypoxia. Biol Reprod 2012, 86:111

22. Nagalakshmi VK, Ren Q, Pugh MM, Valerius MT, McMahon AP, Yu J: Dicer regulates the development of nephrogenic and ureteric compartments in the mammalian kidney. Kidney Int 2011, 79:317-330

23. Harvey SJ, Jarad G, Cunningham J, Goldberg S, Schermer B, Harfe BD, McManus MT, Benzing T, Miner JH: Podocyte-specific 
deletion of dicer alters cytoskeletal dynamics and causes glomerular disease. J Am Soc Nephrol 2008, 19:2150-2158

24. Shi S, Yu L, Chiu C, Sun Y, Chen J, Khitrov G, Merkenschlager M, Holzman LB, Zhang W, Mundel P, Bottinger EP: Podocyte-selective deletion of dicer induces proteinuria and glomerulosclerosis. J Am Soc Nephrol 2008, 19:2159-2169

25. Ibrahim AA, Schmithals C, Kowarz E, Koberle V, Kakoschky B, Pleli T, Kollmar O, Nitsch S, Waidmann O, Finkelmeier F, Zeuzem S, Korf HW, Schmid T, Weigert A, Kronenberger B, Marschalek R, Piiper A: Hypoxia causes downregulation of Dicer in hepatocellular carcinoma, which is required for upregulation of hypoxia-inducible factor 1alpha and epithelial-mesenchymal transition. Clin Cancer Res 2017, 23:3896-3905

26. Kanellis J, Mudge SJ, Fraser S, Katerelos M, Power DA: Redistribution of cytoplasmic VEGF to the basolateral aspect of renal tubular cells in ischemia-reperfusion injury. Kidney Int 2000, 57:2445-2456

27. Rodriguez A, Griffiths-Jones S, Ashurst JL, Bradley A: Identification of mammalian microRNA host genes and transcription units. Genome Res 2004, 14:1902-1910

28. Wu H, Kong L, Zhou S, Cui W, Xu F, Luo M, Li X, Tan Y, Miao L: The role of microRNAs in diabetic nephropathy. J Diabetes Res 2014, 2014:920134

29. Fiorentino L, Cavalera M, Mavilio M, Conserva F, Menghini R, Gesualdo L, Federici M: Regulation of TIMP3 in diabetic nephropathy: a role for microRNAs. Acta Diabetol 2013, 50:965-969

30. Starkey Lewis PJ, Dear J, Platt V, Simpson KJ, Craig DG, Antoine DJ, French NS, Dhaun N, Webb DJ, Costello EM, Neoptolemos JP, Moggs J, Goldring CE, Park BK: Circulating microRNAs as potential markers of human drug-induced liver injury. Hepatology 2011, 54:1767-1776

31. Abdellatif M: Differential expression of microRNAs in different disease states. Circ Res 2012, 110:638-650
32. Creemers EE, Tijsen AJ, Pinto YM: Circulating microRNAs: novel biomarkers and extracellular communicators in cardiovascular disease? Circ Res 2012, 110:483-495

33. Fang M, Du H, Han B, Xia G, Shi X, Zhang F, Fu Q, Zhang T: Hypoxia-inducible microRNA-218 inhibits trophoblast invasion by targeting LASP1: implications for preeclampsia development. Int J Biochem Cell Biol 2017, 87:95-103

34. van den Beucken T, Koch E, Chu K, Rupaimoole R, Prickaerts P, Adriaens M, Voncken JW, Harris AL, Buffa FM, Haider S, Starmans MHW, Yao CQ, Ivan M, Ivan C, Pecot CV, Boutros PC, Sood AK, Koritzinsky M, Wouters BG: Hypoxia promotes stem cell phenotypes and poor prognosis through epigenetic regulation of DICER. Nat Commun 2014, 5:5203

35. Bagheri F, Pusztai C, Farkas L, Kallidonis P, Buzogany I, Szabo Z, Lantos J, Imre M, Farkas N, Szanto A: Impact of parenchymal loss on renal function after laparoscopic partial nephrectomy under warm ischemia. World J Urol 2016, 34:1629-1634

36. Lee H, Song BD, Byun SS, Lee SE, Hong SK: Impact of warm ischaemia time on postoperative renal function after partial nephrectomy for clinical T1 renal cell carcinoma: a propensity scorematched study. BJU Int 2018, 121:46-52

37. Kasahara H, Shimizu H, Yozu R: Postoperative renal function after juxtarenal aortic aneurysm repair with simple cross-clamping. Ann Vasc Surg 2013, 27:291-298

38. Liu KX, Chen Q, Chen GP, Huang JC, Huang JF, He XR, Lin T, Lin QC: Inhibition of microRNA-218 reduces HIF-1alpha by targeting on Robo1 in mice aortic endothelial cells under intermittent hypoxia. Oncotarget 2017, 8:104359-104366

39. Godwin JG, Ge X, Stephan K, Jurisch A, Tullius SG, Iacomini J: Identification of a microRNA signature of renal ischemia reperfusion injury. Proc Natl Acad Sci U S A 2010, 107:14339-14344 